\title{
Orígenes y desarrollo de la teoría de la agenda setting en Comunicación. Tendencias en España (2014-2019)
}

\section{Origins and development of the agenda-setting theory in Communication: trends in Spain (2014-2019)}

\author{
Alberto Ardèvol-Abreu; Homero Gil de Zúñiga; Maxwell E. McCombs
}

Cómo citar este artículo:

Ardèvol-Abreu, Alberto; Gil de Zúñiga, Homero; McCombs, Maxwell E. (2020). “Orígenes y desarrollo de la teoría de la agenda setting en Comunicación. Tendencias en España (2014-2019)". Profesional de la información, v. 29, n. 4, e290414.

https://doi.org/10.3145/epi.2020.jul.14

Artículo recibido el 17-09-2019 Aceptación definitiva: 10-02-2020
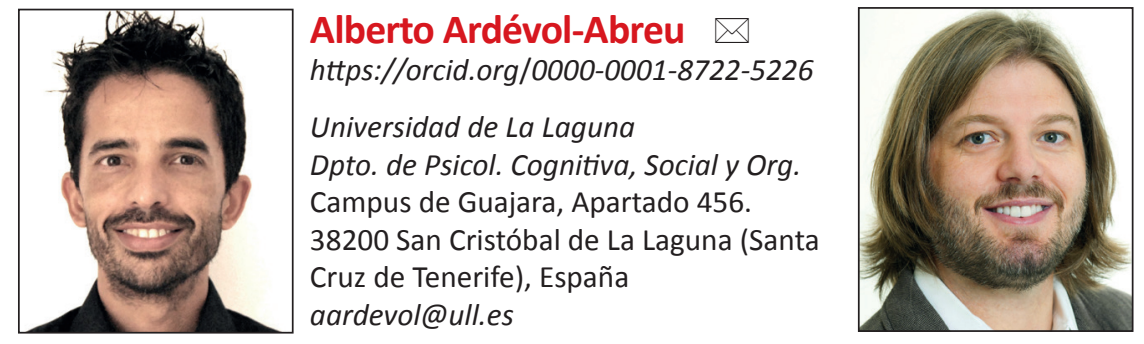

Homero Gil de Zúñiga https://orcid.org/0000-0002-4187-3604

Universidad de Salamanca, España hgz@usal.es

Pennsylvania State University, EUA hgzn@psu.edu

Universidad Diego Portales, Chile homero.gildezuniga@mail.udp.cl

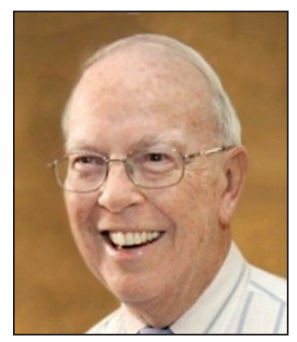

\author{
Maxwell E. McCombs \\ https://orcid.org/0000-0001-5292-0958 \\ Moody College of Communication \\ School of Journalism \\ Belo Center for New Media. \\ 300 W Dean Keeton St. \\ Austin, TX 78712, United States of America \\ maxmccombs@utexas.edu
}

\section{Resumen}

La teoría de la agenda setting establece como hipótesis central que existe un fenómeno de transferencia de relevancia desde la agenda de los medios de comunicación hasta la agenda del público. Desde su formulación en los años 70 del siglo XX, el modelo explicativo de la agenda setting de asuntos (primer nivel) se ha ido ramificando para poder explicar la transmisión de la agenda de los atributos (segundo nivel) y la agenda de redes -o relaciones- (tercer nivel). El presente artículo lleva a cabo una revisión del modelo y su evolución teórica y empírica, para acabar acercándose a su utilización en la investigación publicada en España en el último quinquenio. A pesar de la amplia repercusión de la agenda setting en la investigación publicada en este país, muchos de los trabajos utilizan la teoría como marco general para llevar a cabo análisis de contenido sin llegar a plantear (empíricamente) ningún fenómeno de transferencia de relevancia.

\section{Palabras clave}

Agenda setting; Establecimiento de la agenda; Medios de comunicación; Agenda de los medios; Agenda del público; Efectos de los medios; Comunicación; España; Artículo de revisión. 


\begin{abstract}
The core hypothesis of the theory of agenda setting is that there is a process of transfer of salience from the media agenda to the public agenda. Since its original conception in the early 1970s, the explanatory model of 'issue-agenda setting' (first level) has been extended to help explain the transfer of the media's 'attribute agenda' (second level) and 'network agenda' (third level) to the public agenda. This article provides a review of the agenda-setting model and its theoretical and empirical development, ending with a section that summarizes and discusses research studies published in this area in the last five years in Spain. Despite the broad influence of the agenda-setting theory in communication research in this country, Despite the broad influence of the agenda-setting theory in communication research in this country, many of the studies use the theory as a general framework for conducting a content analysis, withouh empirically testing any process of salience transfer.
\end{abstract}

\title{
Keywords
}

Agenda setting; Agenda building; Media; Media agenda; Public agenda; Media effects; Communication; Spain; Review article.

\section{El modelo de la agenda setting: concepto}

La teoría de la agenda setting, habitualmente denominada 'teoría del establecimiento de la agenda' en español ${ }^{1}$, propone un modelo explicativo de los efectos de los medios de comunicación sobre el individuo y sobre los públicos. La hipótesis central afirma que existe un fenómeno de transferencia de relevancia desde la agenda mediática hasta la agenda del público hasta la agenda del público. Parafraseando a McCombs (2006), los medios dirigen la mirada del público hacia un pequeño conjunto de asuntos acerca de los que vale la pena tener una opinión. Los efectos de la agenda mediática sobre el público se derivan de la accesibilidad de algunas consideraciones sobre otras: los asuntos resaltados por los medios y sus atributos y relaciones serán más accesibles, más fácilmente recuperables de la memoria que otros, y los individuos privilegiarán esos elementos accesibles en los procesos de formación de opinión y de toma de decisiones (Kim; Scheufele; Shanahan, 2002). Se trata por tanto de un proceso eminentemente cuantitativo: a mayor exposición al mensaje, mayor accesibilidad entre el público y mayor efecto agenda.

Una agenda está formada por una colección de asuntos, temas o problemas (primer nivel) o, como se verá más adelante, un conjunto de atributos (segundo nivel), e incluso de temas y atributos conectados en forma de red más o menos compleja (tercer nivel). Mediante estrategias de inclusión, exclusión y énfasis, los medios establecen un ranking de los asuntos del día. Mientras algunos acontecimientos no se elevarán nunca a la categoría de noticias, otros abrirán los informativos televisivos y llenarán las portadas de los periódicos y sus ediciones digitales. Como resultado de estas prácticas rutinarias de producción de información, los medios, además de proporcionar información sobre ciertos hechos, orientan -con éxito- al ciudadano acerca de la importancia que debe otorgarle a cada uno. Esta 'transferencia de relevancia' no ha de ser considerada intrínsecamente mala, pues el consenso social se construye, al menos en parte, gracias a la función indicadora y traductora de los medios. Así, la exposición a los medios de comunicación acerca las posturas e intereses de los diferentes subgrupos demográficos de la población (Shaw; Martin, 1992). Como razonan López-Escobar, Llamas y McCombs (1996), una verdadera sociedad no puede articularse sin una jerarquización de sus prioridades, sin una lista suficientemente breve de asuntos que preocupen a la mayoría de los ciudadanos en cada momento.

Los medios de comunicación desempeñan entonces una función indicadora, que alerta de los cambios que se producen en el entorno (Park, 1940). Pero el espacio y el tiempo del que disponen para relatarlos son limitados, por lo que la selección y jerarquización es indispensable. Internet ha permitido solucionar en parte el problema del espacio disponible para las noticias, pero existen otros impedimentos para poder explicar un conjunto casi infinito de acontecimientos diarios: el número de periodistas es cada vez más reducido, y cada uno de ellos trabaja un número determinado de horas (Le-Masurier, 2015); la capacidad de los individuos para comprender y recordar hechos transformados en noticia también tiene un límite (York, 2013), sobre todo cuando el tiempo que emplea el ciudadano para informarse es cada vez menor, etc.

Si la función indicadora supone la base del primer nivel de la teoría, la función traductora explica el segundo nivel. Las restricciones de tiempo y espacio que se acaban de mencionar provocan que los asuntos importantes del día no puedan ser abordados en toda su complejidad, por lo que las noticias se limitan a señalar unos pocos aspectos del problema que permitan elaborar una versión de la realidad. La selección resultante, forzosamente incompleta, constituirá la agenda de atributos que presentan los medios, que influirá en la agenda de atributos del público, -base del segundo nivel de la teoría-.

Más recientemente, la teoría se ha enriquecido con un tercer nivel, que vendría a cumplir una función asociativa o relacional entre temas y atributos (Guo, 2016; Saldaña; Ardèvol-Abreu, 2016). Los medios tienden a presentar los temas y sus atributos de manera conectada, relacionada, de manera que podría hablarse de una 'red mediática' de objetos y atributos que se entrelazan. El tercer nivel de la teoría establece que estas asociaciones entre asuntos y atributos (agenda de red o de asociaciones) se transfiere desde los medios de comunicación hacia los públicos (Guo, 2016). 
La teoría del establecimiento de la agenda cuestiona el principio de atención y percepción selectiva y, por tanto, la idea de los 'efectos mínimos' predominante hasta el momento en que apareció. Los resultados obtenidos por McCombs y Shaw (1972) en su primer estudio sobre agenda setting resultaban incompatibles con la atención selectiva, pues la correlación entre la agenda mediática y la agenda del público era más alta cuando se consideraba el contenido de los medios en su conjunto que cuando sólo se tomaban aquellos contenidos relativos al partido o al candidato ${ }^{2}$ por el que cada individuo sentía mayor simpatía. El hallazgo sorprendió a los autores, pues de acuerdo con los principios de atención y exposición selectiva, los individuos tienden a evitar -o ignorar- la exposición a información que entra en conflicto con sus actitudes y opiniones previas. Contrariamente a lo esperado, el estudio concluyó que los individuos se ven influidos por el conjunto de mensajes de los medios, aunque no estén en sintonía con sus actitudes y opiniones.

El modelo, tal como fue descrito por McCombs y Shaw en 1972, ha permitido desarrollar una investigación relativamente homogénea en su metodología, algo poco frecuente en los estudios de comunicación en general y en los modelos sobre los efectos de los mensajes en particular. Uno de los puntos fuertes de la agenda setting es precisamente que prescribe un modo particular de tratar con el contenido de los medios: la cantidad de espacio o de tiempo que los medios dedican a un asunto correlaciona con la valoración que el público hace acerca de su importancia.

\section{Origen, antecedentes y evolución del modelo de la agenda setting}

Desde los años 20 del siglo XX, diversos modelos han intentado explicar la influencia de la comunicación de masas sobre los individuos y las sociedades. La mayoría de estos diseños teóricos y de los estudios basados en ellos se centraron inicialmente en la comunicación política -y especialmente la persuasión-, al pretender encontrar los factores que determinan el comportamiento político y el sentido del voto, para después expandirse hacia otros campos de la comunicación.

La primera etapa de los estudios sobre efectos consideraba que la influencia de los medios sobre la sociedad era muy poderosa, y que se ceñía a un modelo simple de estímulo-respuesta. El público, compuesto por una masa uniforme de individuos aislados, se ve desprotegido ante los emisores de la comunicación de masas, que lo manipularían a su antojo. Aunque, como explica De-Moragas-Spà, la teoría de los "efectos ilimitados" (atribuida a menudo e injustamente a Harold Lasswell) nunca se formuló como tal, y fue más bien una construcción posterior "para negarla" (De-Moragas-Spà, 2013, p. 62).

En una segunda fase, a partir de los años 30, se postula que los efectos de los medios de comunicación son más bien limitados, ya que los públicos no se encuentran aislados sino insertos en grupos sociales, que son los verdaderamente importantes en el modelado de la opinión pública. Katz y Lazarsfeld (2006), en un trabajo que vio la luz en 1955, exponen esta idea mediante su teoría de two-step flow of communication ${ }^{3}$ : la comunicación mediática llegaría a los públicos indirectamente, pasando primero por los líderes de opinión de los diferentes grupos sociales, que serían los más sensibles al efecto de los medios. A finales de los 60, algunos investigadores comienzan a abandonar la idea de los efectos limitados. Se trata de la tercera y última fase, en la que se habla a la vez de efectos fuertes y efectos débiles, y de fenómenos condicionales. Se encuadran en esta tendencia teorías como la agenda setting, el framing y la teoría del cultivo.

La teoría de la agenda setting ha constituido en las últimas cinco décadas (especialmente en los años 70 y 80 ) uno de los paradigmas más influyentes y fértiles en la investigación en comunicación (Bryant; Miron, 2004). Parte de su éxito y de su rápida difusión se debió a que consiguió acabar con décadas de trabajo frustrante entre los investigadores, que no acababan de demostrar una conexión entre los medios y las ideas y actitudes de los públicos. Para Kosicki (1993), la teoría originó un cambio de paradigma en la disciplina, ya que alejó a los investigadores del modelo de los "efectos limitados" y los introdujo de nuevo en la búsqueda de "efectos fuertes".

Las primeras investigaciones basadas en el modelo de la agenda, no obstante, valoraban el poder persuasivo de los medios de manera cautelosa. La ruptura con los "efectos limitados" era sólo parcial, como lo ilustra la conocida frase de Cohen que inspiraría el modelo de la agenda setting:

"La prensa no tiene mucho éxito en decir a la gente qué tiene que pensar, pero sí lo tiene en decir a sus lectores sobre qué tienen que pensar" (Cohen, 1963, p. 13).

Esta idea precursora, recogida por McCombs y Shaw una década más tarde como metáfora del primer nivel de su modelo, se iría ampliando a medida que los estudios basados en la agenda setting hallaban evidencia empírica de los efectos persuasivos de los medios: la prensa también tiene éxito en decir a sus lectores qué tienen que pensar, y con qué asociarlo.

La teoría de la agenda setting presenta fuertes conexiones con las ciencias de la información, la psicología, las ciencias políticas, la sociología o la pedagogía, ya que su objeto de estudio se mueve en los límites de un gran número de especialidades (Kosicki, 1993). El modelo, como reconoce el propio McCombs, se inspira en las ideas que Lippmann (2003) plasmó en su 
obra más conocida, publicada por primera vez a principios de los años 20: Public opinion. A principios del siglo XX, Lippmann se atreve a hablar de la imposibilidad de los ciudadanos para tomar decisiones sobre asuntos complejos, sobre los que no tienen un conocimiento directo, poniendo en tela de juicio la base misma de la democracia y de los gobiernos representativos. "Las imágenes de nuestra mente", obtenidas en muchos casos a través de lo que los medios cuentan, tienen un reflejo en el mundo real, ya que las personas actúan en función de sus actitudes y creencias. En otras palabras, la imagen del mundo no es el mundo, pero con frecuencia se toma como tal, del mismo modo que los hombres encadenados en la caverna platónica consideraban que la realidad eran las sombras que desfilaban ante ellos.

Estas reflexiones constituyen, de alguna manera, la esencia de la teoría de la agenda desarrollada medio siglo después. En fechas tan tempranas, y mediante la revisión de estudios de su época, Lippmann pone de manifiesto la coincidencia entre lo que los públicos consideran importante y lo que los editores deciden llevar a las páginas de sus periódicos. La sociedad moderna confía en que la prensa resuelva todas las deficiencias de las instituciones, proporcionando a los ciudadanos hechos verdaderos en forma de noticias. Estos hechos serían capaces de crear una opinión pública omnicompetente, con una opinión sobre todos los asuntos discutibles, que podría llevar al conjunto de la sociedad al máximo bienestar gracias al sufragio y a los gobiernos representativos. La realidad es que esa responsabilidad es demasiado grande para una prensa que selecciona algunos acontecimientos y los saca de la oscuridad en detrimento de otros, iluminándolos uno a uno y creando una imagen del mundo que no es el mundo (Lippmann, 2003).

\section{Tipos de agenda: agenda de los medios, agenda del público y agenda política}

Los estudios de agenda setting han fundamentado sus modelos de transferencia de relevancia a través de tres tipos principales de agenda: la agenda de los medios, la del público y, con menos frecuencia la política. La agenda de los medios está compuesta por el conjunto de asuntos a los que unos medios de comunicación determinados prestan atención de manera preferente en un momento dado, y se reconstruye habitualmente mediante técnicas de análisis de contenido.

Para McLeod, Becker y Byrnes (1974) existen a su vez tres tipos de agenda del público: intrapersonal, interpersonal y la pública percibida. La agenda intrapersonal está constituida por el conjunto de temas que, desde un punto de vista subjetivo, resultan más importantes para el individuo. A diferencia de esta, la agenda interpersonal es la formada por los asuntos acerca de los que el individuo discute con los demás, y alude a una relevancia intersubjetiva. El tercer tipo de agenda pública sería la formada por los temas que el individuo considera que son importantes para los demás: es lo que Wolf (2000) califica de "clima de opinión".

Para reconstruir la agenda del público se utilizan encuestas (en las que los casos de análisis son individuos) o sondeos de opinión (que aportan datos porcentuales agregados sobre el estado de la opinión pública sobre un tema determinado). En Estados Unidos, los investigadores suelen emplear sondeos que elaboran entidades como Gallup, lo que simplifica la recogida de datos sin perder rigor metodológico. En España se han empleado con frecuencia los barómetros publicados por el Centro de Investigaciones Sociológicas (por ejemplo, en Rodríguez-Díaz; Castromil, 2010). Los sondeos de opinión pública utilizados para confeccionar la agenda del público incluyen alguna variante de la pregunta que Gallup viene formulando a sus encuestados de manera periódica desde los años 30:

“¿Cuál piensa usted que es el problema más importante que ha de afrontar hoy este país?”.

La agenda pública se confecciona utilizando los asuntos que son mencionados como los más importantes por un determinado porcentaje de los encuestados, habitualmente igual o superior al 10\%. El número de ítems que superan esta barrera suele ser reducido, habitualmente de sólo cinco o seis (McCombs; Evatt, 1995), lo que ha servido como argumento para afirmar que la agenda del público tiene una capacidad limitada. Perspectivas más recientes, en cambio, señalan que esta agenda de problemas más importantes es sólo la agenda priorizada por los ciudadanos, y que la conversación cívica y sobre asuntos de interés público es en realidad mucho más amplia. Hoy en día parte de esta discusión más extensa sobre asuntos de relevancia social está disponible para su análisis y observación a través de las redes sociales, blogs y sitios web, configurando una agenda de asuntos de los medios sociales (social media issue agenda) que es mucho más dilatada que las conceptualizaciones originales de la agenda pública de asuntos (McCombs; Shaw; Weaver, 2014). La agenda de medios sociales es sin embargo de naturaleza híbrida, pues incluye contribuciones originales del público (temas y asuntos de los que se hablan, al margen del estímulo de los medios informativos), lo que añade complejidad a los efectos tradicionales de transferencia vertical (influencia desde los medios a las audiencias) (Meraz, 2011).

Por su parte, la agenda política comprende el conjunto de asuntos de los que los políticos o las instituciones se ocupan en cada momento, ya sea mediante la acción (desarrollando políticas concretas) o el discurso (hablando sobre ellos). La distinción entre agenda política y agenda de los políticos se refiere al carácter consensuado o no de los temas relevantes. Mientras la primera estaría compuesta por los asuntos considerados importantes por los políticos como grupo (un partido, el Gobierno, etc.), la segunda se corresponde con las prioridades definidas por cada político como individuo. Algunos autores consideran en cambio que la agenda política es parte de la agenda pública. Zhu (1992), por ejemplo, sostiene que la agenda pública está compuesta por cinco elementos o subagendas: de los grupos de interés, mediática, del público, de los políticos y política. 


\subsection{Tamaño restringido de las agendas}

El número de asuntos a los que una sociedad o un individuo pueden atender en un momento determinado es limitado. La idea proviene de la psicología cognitiva, de una generalización de lo que George Miller denominaba "el número mágico siete, más o menos dos" (citado por McCombs, 2006, p. 84), que hace referencia al número de ítems que podían almacenarse en la memoria a corto plazo. Otros estudios posteriores (por ejemplo, Cowan, 2001) afirman que el número es en realidad más reducido, entre tres y cinco. Ante una sobrecarga de información, o bien se limita la entrada de nuevos datos (pérdida de atención) o se disminuye el rendimiento (afectando a los procesos de comprensión, memorización, etc.).

Como ya se ha mencionado, la capacidad informativa de los medios es también limitada, frente a un número de acontecimientos de interés social prácticamente infinito. La duración de los informativos de radio y televisión, la superficie de las páginas del periódico, la jornada de trabajo de los periodistas, etc., imponen un límite. Pero, cla agenda mediática tiene las mismas características hoy que hace cuatro décadas, cuando comenzó la investigación en agenda setting?

La digitalización de la información está provocando la segmentación de los públicos en función de sus gustos, preferencias e intereses, por lo que puede aventurarse que las agendas mediática y social están sufriendo cambios. Quizá la multiplicación de los medios de comunicación disponibles permita la coexistencia de una gran variedad de agendas mediáticas, por lo que el efecto final sobre el público podría ser diferente. Pero decimos quizás, porque no está tan claro que una mayor cantidad de medios traiga consigo una mayor diversidad de temas o de enfoques, ni en la agenda mediática ni en la agenda social. Cabe la posibilidad de que, con la llegada de internet y las nuevas posibilidades que ofrece la televisión por cable, satélite y TDT, no se logre configurar un coro polifónico de puntos de vista, opiniones, encuadres, etc., ya que la fuerza de las normas y hábitos periodísticos pueden condenar al sistema mediático a un alto nivel de redundancia (McCombs, 2006).

\section{Marco temporal de los efectos de agenda}

[...] Los efectos de fijación de agenda no son en absoluto instantáneos, pero sí que se dan relativamente a medio plazo (McCombs, 2006, p. 93).

Los efectos de la transferencia de relevancia no son inmediatos ni duran indefinidamente, por lo que cualquier estudio empírico ha de tener en cuenta los marcos temporales en los que se producen los efectos de la agenda setting si pretende llegar a alguna conclusión válida. La literatura especializada se refiere a estos marcos utilizando conceptos como período de latencia, tiempo de mantenimiento o tiempo en caída (Watt; Mazza; Snyder, 1993; McCombs, 2006). Como principio general, toda causa ha de producirse antes que su efecto, por lo que en el diseño de la investigación ha de tenerse claro cuál es la agenda desde la que se produce la transferencia y cuál es la que recibe su influencia.

El tiempo que ha de transcurrir para que el estímulo (aparición de un tema en la agenda mediática) ocasione una respuesta (transferencia de relevancia de ese tema hasta la agenda pública) se denomina período de latencia. Una vez aparece la correlación entre ambas agendas, el efecto aumenta hasta alcanzar un valor que se mantiene durante un tiempo más o menos largo, que se denomina tiempo de mantenimiento. A partir de un determinado momento, la correlación empieza a disminuir hasta que deja de ser significativa: es el tiempo en caída. El momento óptimo para observar la agenda pública, por tanto, es el tiempo de mantenimiento (McCombs, 2006). La figura 1 explica de manera simplificada los marcos temporales considerados habitualmente en la teoría de la agenda setting.

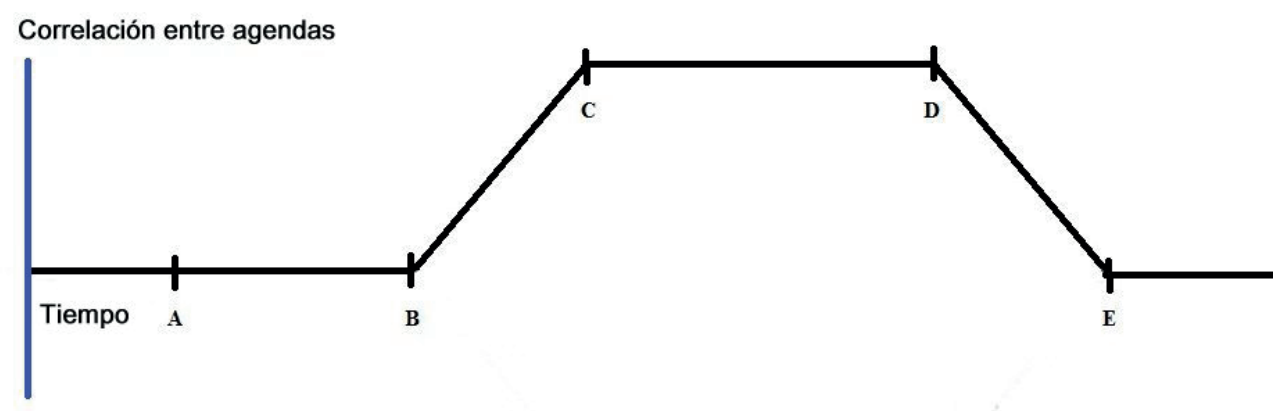

A: Estímulo (aparición de un tema en la agenda mediática)

B: Respuesta (aparición de ese tema en la agenda del público)

A-B: Período de latencia
C: Máxima correlación entre agendas

C-D: Tiempo de mantenimiento

D-E: Tiempo en caída

Figura 1. Marcos temporales de los efectos de agenda setting

Nota: La figura muestra los marcos temporales de manera simplificada, pues las curvas reales no tienen un perfil tan recto. Como se muestra en el trabajo de Watt et al. (1993), la correlación entre agendas varía en cada momento, con un pico dentro de lo que hemos denominado tiempo de mantenimiento. 
La mayor parte de los estudios empíricos basados en el modelo de la agenda setting llevan a cabo análisis de contenidos de una muestra de medios (agenda mediática) para contrastarlos con los datos obtenidos mediante encuestas o sondeos (agenda pública). Este modo de proceder obliga a conocer (o al menos, a aventurar) cuánto tiempo transcurre entre la causa y el efecto. Si se dispone de un sondeo o una encuesta finalizada en una fecha determinada, no será lo mismo analizar el contenido de los medios del día anterior, de la semana anterior, del mes anterior o del año anterior. Diferentes autores ofrecen resultados variables en función de la metodología empleada, del medio de comunicación y del tema estudiado.

Algunas investigaciones han considerado cortos períodos de tiempo de latencia, mientras otras emplean períodos más largos: días, quincenas, meses, semanas... Los diferentes resultados obtenidos han servido para distinguir los efectos de la exposición a corto y a largo plazo y para demostrar la robustez de la teoría. Otros diseños han variado los intervalos temporales para buscar un período óptimo, un momento en el que la correlación entre las agendas sea máxima. Para Kosicki (1993), esta heterogeneidad metodológica no ha llevado aparejada una discusión teórica apropiada acerca de porqué se producen diferentes efectos (o ninguno) en función del tiempo transcurrido tras la exposición al mensaje.

Winter y Eyal (1981), empleando The New York times como indicador de la agenda de los medios, encuentran que el período de latencia puede oscilar entre las cuatro y las seis semanas. Stone y McCombs (1981), tomando como medios de estudio las revistas Time y Newsweek, sugieren un período más largo, de dos a seis meses, aunque advierten de que estos tiempos podrían variar en función de los temas estudiados. Los trabajos más modernos acortan el período de latencia, quizá por los cambios experimentados en los ritmos de producción y de consumo de noticias, cada vez más rápidos. Así, Wanta y Roy (citado por Rodríguez-Díaz, 2001) consideran que el período óptimo (máxima correlación) se produce entre cuatro y cinco días después de la cobertura si se trata de una televisión nacional, entre seis y siete días si se considera una televisión local y en 15 días en un periódico local.

Watt, Mazza y Snyder (1993) concluyen que los asuntos menos relacionados con la experiencia directa (en su estudio, noticias sobre Irán y la Unión Soviética) alcanzan la máxima correlación entre agendas entre los 12 y los 120 días, mientras que los más experienciales (inflación) encuentran su máximo efecto en 18 meses. Tras constatar estas diferencias, los autores afirman que no tiene sentido definir marcos temporales genéricos, ya que los diferentes asuntos presentan diferentes períodos de latencia y tiempos de mantenimiento, dependiendo de variables como el carácter experiencial o no experiencial del asunto o del tiempo que lleve en la agenda mediática. La larga cobertura de un tema determinado tiende a agotar la atención del público, por lo que difícilmente se podrán encontrar efectos de agenda. Un elevado compromiso emocional con la información también puede afectar a los marcos temporales, acortando el período de latencia (McCombs, 2006). Lo más razonable puede ser escoger un intervalo que se haya demostrado adecuado en un estudio con un diseño similar al que se pretenda llevar a cabo.

\section{Factores que median en el fenómeno de transferencia de relevancia}

Una vez se hubo demostrado que la selección de temas llevada a cabo por los medios se transfería a la agenda de los públicos, los investigadores se plantearon qué variables podían aumentar o disminuir la magnitud de ese fenómeno. Ya en el estudio original de Chapel Hill, McCombs y Shaw (1972) se dieron cuenta de que no todos los medios de comunicación fijaban la agenda de manera uniforme entre todos los grupos de ciudadanos. Se encontraron efectos diferentes en función del medio de comunicación y de las características del público. Los fundadores de la teoría de la agenda setting aventuraron pronto explicaciones para esta diversidad de efectos entre los diferentes públicos, basadas en la influencia de la necesidad psicológica de orientación, la influencia de la comunicación interpersonal o la experiencia directa. También se sugirió que el tipo de medio de comunicación (prensa, radio o televisión) podía jugar un papel en los efectos producidos (McCombs; Shaw, 1977).

\subsection{Fuerza relativa de los diferentes medios: prensa, televisión y medios online}

A pesar del tiempo transcurrido, el debate académico sobre las diferencias entre los medios a la hora de configurar la agenda está lejos de concluirse (Walgrave; Van-Aelst, 2006). Aunque se han podido comprobar efectos de transferencia de relevancia en periódicos, radio, televisión e internet ${ }^{4}$, la mayoría de los estudios que han comparado diferentes medios apuntan a una mayor influencia de los periódicos, pese a que la mayoría de los ciudadanos se informe a través de la televisión ${ }^{5}$ (Protess; McCombs, 1991). La función de la televisión en la configuración de la agenda pública podría ser complementaria de la de los periódicos: McCombs (1976, citado por Wolf, 2000) atribuye el papel de agenda setters a los periódicos, mientras que la de la televisión sería de enfatización o spot-lighting. De esta manera, la agenda del público estaría organizada en primera instancia por los periódicos (hoy en día, prensa digital), y la televisión podría reconstruir y reorganizar algunos de los temas introducidos por los primeros. Para Mohamed y Gunter (2009), los periódicos juegan un papel determinante en la configuración de la agenda pública más estable, mientras que el impacto de la televisión es más bien a corto plazo.

Esta superioridad de los periódicos como fijadores de agenda suele atribuirse al mayor tiempo que el lector dedica al periódico o a la posibilidad de relectura que no brinda la televisión, lo que confiere mayor fugacidad a sus mensajes. Para Wanta (1997), a pesar de que la televisión ofrezca al público imágenes, sonido y movimiento de los acontecimientos que narra, la mayor influencia de los periódicos se debe a su carácter de fuente permanente de información, pues se 
encuentra disponible a cualquier hora del día (igual que la información en internet). En el mismo sentido, Wolf (2000) considera que las noticias en televisión, por su brevedad y falta de contextualización y profundización, constituyen un conjunto fragmentado de información que difícilmente puede ejercer un efecto de agenda relevante.

Entre los periódicos, no todos tienen la misma capacidad para imponer su agenda, pues son los diarios de referencia los que marcan la agenda para otros periódicos e incluso para otros medios (radio y televisión), a través de un proceso conocido como inter-media agenda-setting ${ }^{6}$. Danielian y Reese (1989) demostraron que la agenda de los informativos de televisión incluía problemas relacionados con las drogas cuando ese asunto era tratado en los periódicos. Golan (2006) comprobó cómo The New York Times condiciona la agenda internacional de tres informativos nocturnos de televisión en Estados Unidos.

En el entorno de la comunicación online, el estudio de la fortaleza de los efectos de agenda de los medios digitales y las redes sociales presenta algunas particularidades que deben ser mencionadas en este epígrafe. Por una parte, los medios digitales han provocado una expansión en el número de asuntos y de atributos que contienen las agendas, tanto de los medios como de los públicos -más difíciles de separar, ya que ambas conviven en las redes sociales y no siempre existe una línea divisoria entre emisores y receptores-. Existen medios de nicho y audiencias específicas con intereses innumerables. Por otra, los investigadores disponen de una gran cantidad de datos que les permiten incluir agendas del tamaño que estimen (desde unos pocos asuntos hasta una cantidad potencialmente enorme de temas que se mencionan en las conversaciones online). En este sentido, hay que tener en cuenta que la transferencia de relevancia sucede cuando hay un alto grado de redundancia en los mensajes recibidos por el público, y ante agendas demasiado extensas es poco probable encontrar un alto grado de correspondencia. Dicho de otra manera, en un entorno mediático fragmentado los efectos de agenda van a ser en general menores, especialmente cuando se estudian asuntos con bajo grado de redundancia (Atkinson; Lovett; Baumgartner, 2014; McCombs; Shaw; Weaver, 2014).
Los medios digitales han provocado una expansión en el número de asuntos y de atributos que contienen las agendas, tan- to de los medios como de los públicos

\subsection{Relevancia e incertidumbre en la transferencia de la agenda mediática: la necesidad de orientación}

El ser humano presenta una necesidad innata de orientación, de comprensión del mundo que le rodea, especialmente de lo más inmediato. La necesidad de orientación se manifiesta en todos los ámbitos que el individuo percibe como importantes para su vida o para la sociedad de la que forma parte (relevancia) y sobre los que no tiene información (incertidumbre). Relevancia e incertidumbre, por tanto, determinarán la necesidad de orientación del individuo (McCombs, 2002). De manera general, puede afirmarse que una mayor necesidad de orientación en torno a un asunto provoca una mayor "vulnerabilidad" o receptividad a los efectos de la agenda de los medios.

La influencia de los medios sobre la atribución de relevancia y la disminución de la incertidumbre es muy grande. Por un lado, como ha demostrado el modelo de la agenda setting, son los propios medios los que sugieren qué asuntos son relevantes, y por otro, también son ellos los que, al menos en parte, sacian la necesidad de información que previamente han generado. La máxima influencia de los medios (y de los efectos de la agenda) tendrá lugar cuando el individuo percibe un asunto como relevante pero dispone de poca información sobre él, lo que le crea incertidumbre. La mínima tendrá lugar entre los individuos que perciben un asunto como poco relevante y además se encuentra informado sobre él (relevancia e incertidumbre baja). No obstante, la necesidad de orientación varía entre los individuos como diferencia individual, pues una misma situación puede requerir de gran cantidad de información para una persona y de ninguna para otra.

\subsection{La experiencia personal como factor moderador de los efectos de la agenda}

"La experiencia personal puede ser un maestro más poderoso que los medios de comunicación, cuando los temas tienen un impacto directo sobre la vida de uno" (McCombs, 2006, p. 36).

Los medios de comunicación son una fuente de conocimiento del mundo social. Existen algunos asuntos públicos sobre los que los ciudadanos pueden tener una experiencia directa, de primera mano, con la que contrastar aquello que leen, escuchan o ven en los medios. En otras ocasiones en cambio, la única fuente de información son los medios, por lo que la experiencia del público será vicaria, indirecta. La inflación puede ser un ejemplo del primer tipo de asuntos, mientras que el estado de la balanza de pagos del país podría ser un ejemplo del segundo (McCombs, 2006). La influencia de la agenda de los medios es mayor en temas no experienciales ${ }^{7}$ que en temas experienciales. Resulta lógico, puesto que si el público no tiene un modo de contrastar lo que lee, difícilmente podrá formarse una imagen mental distinta a la que reproducen los medios. En cambio, si se puede conocer un asunto de primera mano, la influencia de los medios será mucho menor, puesto que la experiencia directa es considerada más fiable que la vicaria.

En diversos estudios (por ejemplo, Winter; Eyal; Rogers, 1982) se ha podido demostrar la mayor capacidad de los medios para imponer su agenda en los temas lejanos o no experienciales. En un análisis sobre las noticias internacionales en los medios de comunicación estadounidenses, Zhang y Meadows (2012) sugieren que el desigual tratamiento informativo que se otorga a los diferentes países puede ejercer un efecto determinante en la visión que el público estadounidense se hace del mundo. En la misma línea, Wanta, Golan y Lee (2004) afirman que la influencia de los medios es más 
decisiva en los asuntos referidos a naciones extranjeras, pues para el gran público no existe ninguna otra fuente de información. Estas ideas germinaban ya en el primer estudio empírico sobre la agenda setting en Chapel Hill (McCombs; Shaw, 1972). En él se afirmaba que la correlación observada entre la agenda mediática y la social no podía ser accidental, puesto que el único modo que los ciudadanos tenían para acercarse a la "arena política" era a través de los medios de comunicación de masas: no había fuentes de información alternativas.

\subsection{Otras variables moderadoras: exposición a los medios, experiencia previa y factores socioeconómicos}

Pocos años después del estudio original de Chapel Hill, comenzó a estudiarse el papel de ciertas variables individuales como la orientación política, el grado de exposición a los medios o el interés por los asuntos que se tratan. En general, puede afirmarse que la magnitud de los efectos de la agenda depende del tipo e intensidad de exposición a los medios, así como de la experiencia y las actitudes previas hacia los elementos (asuntos) que componen la agenda. La influencia del nivel educativo y de otras variables socioeconómicas, en cambio, no está tan clara.

Una mayor exposición a los medios de comunicación tiende a aumentar el efecto de la agenda mediática, al menos mientras no se introduzcan otras variables. MacKuen (1984) planteó una relación compleja entre la exposición a los mensajes y el impacto provocado por ellos a través de la variable interés. Un mayor interés del individuo por los asuntos políticos provoca una mayor exposición a los medios de comunicación, a la vez que disminuye la importancia del fenómeno de transferencia de relevancia. El interés por tanto, desempeñaría un papel "protector" para el individuo, a pesar de condicionar una mayor exposición a los medios. Sin embargo, otros estudios han obtenido resultados opuestos, concluyendo que el interés, a través de un mayor conocimiento sobre un asunto, incrementa la susceptibilidad a los efectos de la agenda mediática (ver detalles en Wanta, 1997).

La experiencia del individuo en torno a un asunto parece aumentar las posibilidades de integración, es decir, de acomodación de la información nueva en un esquema amplio y preestablecido, disminuyendo así la influencia de acontecimientos puntuales y, por tanto, de la transferencia de relevancia. Es lo que Wolf (2000, p. 174) denomina "persuasión templada por la persistencia": los receptores del mensaje tienden a integrar su agenda subjetiva con la propuesta por los medios, moderándose así la influencia de estos últimos.

Los hallazgos sobre el papel que juega el nivel educativo han sido con frecuencia contradictorios. Cuando se encuentra un mayor efecto de agenda en los individuos con un mayor nivel educativo, suele argumentarse que su mayor capacidad y disposición para enfrentarse a contenidos abstractos y reflexionar sobre ellos los hace más sensibles a los medios. Para que haya un efecto debe haber una exposición, una comprensión y una integración del mensaje percibido, lo que explicaría ese mayor efecto en los individuos formados. En cambio, cuando se obtiene el resultado contrario, se argumenta que los individuos más formados poseen agendas más sólidas, ancladas en su mayor conocimiento de la realidad y en sus marcos de interpretación más asentados ${ }^{8}$. Este hecho los protege de los efectos de los medios, haciéndolos relativamente inmunes a los datos puntuales (MacKuen, 1984).

En el estudio que dio origen a la teoría de la agenda, McCombs y Shaw (1972) argumentaban que los individuos más formados y con mayor interés en la política eran los menos propensos a cambiar sus convicciones, es decir, los más resistentes a los efectos de los medios. A medida que dispone de mayor soporte empírico para la teoría, McCombs (2006) corrige esta impresión inicial y manifiesta que un mayor nivel educativo y una mejor formación provocan un aumento en la exposición y la atención a los medios, ampliando la gama de asuntos a los que el individuo es sensible, sin que se produzca por ello una mayor resistencia psicológica a la aceptación de la agenda mediática: el individuo más formado, por tanto, será el más vulnerable.

No concluyen lo mismo Canel, Llamas y Rey-Lennon (1996), para quienes los individuos más formados son más resistentes al efecto de los medios, al tener una mayor capacidad crítica. En el mismo estudio, se valoró la influencia de algunos factores socioeconómicos en la transferencia de relevancia desde la agenda de los medios hasta la agenda de los públicos, como el sexo y la ideología. De acuerdo con sus resultados, los varones y los votantes de derecha se verían menos influenciados por la agenda mediática, mientras que los menos formados, las mujeres y los votantes de izquierda serían más vulnerables.

\section{Extensiones del modelo original de agenda setting}

El postulado original del modelo de la agenda establece que un conjunto de noticias puede modelar la percepción del público acerca de cuáles son los asuntos más importantes del momento. Esta hipótesis se desarrolla sobre una idea central, que es la de la transferencia de relevancia de una agenda hacia la otra, y que ha servido como soporte para un buen número de trabajos y líneas de investigación que extienden el modelo respetando esta base. McCombs considera legítimas estas nuevas vías de exploración, y cree que el estudio de campos como la educación, la economía, las finanzas o la religión pueden beneficiarse de su teoría (Rodríguez-Díaz, 2004). En España, en una deriva totalmente novedosa, el modelo de la agenda ha sido empleado para explicar la transferencia de relevancia desde la agenda del profesor hasta la agenda de los alumnos, convirtiendo al docente en un agenda setter (Rodríguez-Díaz, 2004). A continuación, se resumen las extensiones al modelo original más relevantes de las últimas décadas. 


\subsection{Segundo nivel de la teoría: la agenda de atributos}

La mayor parte de la investigación sobre agenda setting se ha centrado en los temas o asuntos tratados por los medios y transferidos al público, obviando en gran medida otras agendas sugeridas en la investigación temprana (McCombs; Evatt, 1995). Una de estas agendas ha sido la agenda de atributos, formada por características o aspectos parciales de los temas o asuntos. Mientras que un objeto es cualquier asunto hacia el que dirigimos nuestra atención o sobre el que tenemos una actitud, los atributos son el conjunto de características, rasgos y propiedades que definen esos objetos (McCombs, 2006, p. 139). Cuando los medios deciden resaltar un asunto, lo hacen a través de algunas de sus características o propiedades, pero no de todas ellas. Manteniendo la metáfora central de la transferencia de relevancia, en esta extensión del modelo original se argumenta que la agenda de atributos de los medios sobre un determinado objeto -por ejemplo, un candidato político- se transmite hacia el público, del mismo modo que sucede con la agenda de objetos. Siguiendo con el ejemplo político, el candidato puede representarse en los medios como honesto e inteligente o como mentiroso y torpe, por lo que los medios pueden contribuir en gran medida a la construcción de su imagen pública (Weaver et al., 1981). De acuerdo con este segundo nivel de la teoría, los medios no sólo tendrían éxito al transmitir al público "sobre qué" pensar, sino también "qué" pensar.

Mientras que un objeto es cualquier asunto hacia el que dirigimos nuestra atención o sobre el que tenemos una actitud, los atributos son el conjunto de características, rasgos y propiedades que definen esos objetos

McCombs (2006) considera que influir en la agenda de atributos de un objeto constituye un modo de definir los términos del debate público, lo que a su vez constituye el máximo exponente del poder político. Se trata de un efecto mucho más sutil y complejo que el descrito en el primer nivel de la teoría, ya que la cantidad de atributos asociados a un objeto puede ser enorme. Mientras la transmisión de la relevancia de un objeto se relaciona con la atención que el público presta a ese objeto, la transmisión de la relevancia de un atributo proporciona elementos para la comprensión de ese objeto. La agenda de atributos se construye, por tanto, mediante un proceso sistemático de inclusión y de exclusión de los aspectos de un determinado objeto. A su vez, los atributos que los medios resaltan acerca de los diferentes temas suelen variar con el tiempo, por lo que la foto de la agenda de atributos no es fija.

El segundo nivel del modelo de la agenda entronca con la teoría del framing o encuadre noticioso (Ardèvol-Abreu, 2015). Para McCombs (2006), los frames no son más que agendas complejas de atributos que (McCombs; Evatt, 1995):

- definen un tema;

- provocan que el público comprenda los asuntos desde una perspectiva determinada;

- condicionan la preferencia de una solución determinada para el problema, en lugar de otras.

El proceso de encuadre o framing influye entonces en la interpretación de la realidad, en la formulación de juicios y en la expresión de opiniones de los individuos.

\subsection{Tercer nivel de la teoría: la agenda de redes o network agenda setting}

De muy reciente aparición, y aún en fase de desarrollo teórico y empírico, el tercer nivel de la teoría toma parte de sus fundamentos teóricos de los modelos de memoria asociativa humana. Según estos modelos, las representaciones mentales que reproducen la estructura del mundo físico y social -las 'imágenes en nuestras cabezas'- se basan en asociaciones (redes) más o menos complejas de frases, palabras, objetos, atributos, valores, motivos, emociones, etc. (Price; Tewksbury, 1997; Quilian, 1968; Guo, 2016). El tercer nivel de la teoría o network agenda setting (NAS) postula que los medios de comunicación tienen la capacidad de construir y remodelar estas redes asociativas, tanto en los mensajes que distribuyen (agenda de redes de los medios) como en la memoria a largo plazo de sus audiencias (agenda de redes de los públicos).

La agenda de redes de los medios activaría así en las 'mentes' de sus públicos una red cognitiva de relaciones que en mayor o menor grado se correspondería con las relaciones construidas en los mensajes informativos. En palabras de Guo, la hipótesis central del modelo de NAS establece que

"la prominencia de las redes de objetos y atributos en los medios de comunicación influencia [o se transfiere a] la prominencia de las redes de estos elementos entre el público" (Guo, 2016, p. 5).

Podría decirse entonces que los medios tienen éxito a la hora de transmitir al público cómo debe asociar diferentes mensajes para reconstruir y comprender la realidad social (Guo, 2016, p. 3; Guo, 2012; 2013; Vu; Guo; McCombs, 2014). Por ejemplo, si los medios enfatizan de manera recurrente un supuesto nexo entre la llegada de refugiados a Europa y los ataques terroristas, el público considerará que ambos asuntos están relacionados (fenómeno de aplicabilidad). Como en este ejemplo, las redes asociativas pueden limitarse a dos constructos (díada inmigración y terrorismo), pero también pueden abarcar tres (tríada inmigración, terrorismo y desempleo) o, más habitualmente, redes complejas de objetos y atributos. Cuanto más frecuentemente se activen (mencionen conjuntamente) estas redes de constructos, más disponibles estarán para la comprensión y la toma de decisiones en la memoria a corto plazo de público (fenómeno de accesibilidad). 


\subsection{Agenda building: ¿Quién configura la agenda mediática?}

McCombs (1992) establece cuatro fases en la historia de la investigación en torno al modelo de la agenda. La última de ellas (penúltima, si incluimos el tercer nivel de la teoría) corresponde al estudio de los procesos de construcción de la agenda de los medios, denominada en inglés agenda building. Si se considera que los medios tienen éxito en definir los términos del debate público y en decir a sus públicos en qué y cómo deben pensar, o cómo deben asociar los mensajes, el verdadero poder residirá en la capacidad para configurar la agenda mediática.

Las razones que llevan a los profesionales de la información a elegir unos temas en lugar de otros -es decir, construir el primer nivel de la agenda- han sido recopiladas por varios autores bajo la denominación de "criterios de noticiabilidad o valores noticiosos". Para Wolf (2000), los valores noticiosos presentan una gran homogeneidad en la cultura profesional periodística, pero no por ello son rígidos: cambian a lo largo del tiempo y pueden ser aplicados con cierta flexibilidad en el seno de un medio. Wolf considera que los valores noticiosos derivan de las propiedades sustantivas de las noticias, de la disponibilidad de material, de las propiedades del producto informativo y de las características del público y de la competencia. La aparición de una noticia en la primera plana de un periódico o en la parte inferior de una página par, su mayor o menor duración en un informativo televisivo o radiofónico o el tamaño que ocupa en la página de inicio de un medio digital denotan la importancia que los profesionales de la información han otorgado al acontecimiento que está en el origen de esa noticia. Entonces, ¿̇los periodistas son independientes al configurar la agenda informativa?, ¿̇se guían sólo por criterios más o menos objetivos, compartidos por la mayoría de los profesionales? ¿Qué relación existe entre los criterios de noticiabilidad y el poder de los diferentes actores para construir la agenda de los medios?

A tenor de la cantidad de investigaciones que estudian la relación entre la agenda política (o de los políticos) y la agenda mediática, el mundo de los políticos parece ser el lugar en el que hay que empezar a indagar para estudiar la configuración de la agenda de los medios. Los resultados obtenidos en diversos trabajos empíricos, sin embargo, sugieren que las influencias no son tan unidireccionales como puede parecer, ya que en ocasiones se concluye que son los medios los que configuran la agenda política, mientras que en otras se afirma lo contrario (Tedesco, 2001; Walgrave; Aelst, 2006). En una revisión de 19 investigaciones sobre la capacidad de los medios para condicionar la agenda política, se encontró que ocho de ellas constataban una gran influencia de la agenda mediática sobre la política, cuatro detectaban una influencia considerable y siete una influencia débil o nula. Para los autores, las divergencias en los resultados se explican porque la capacidad de los medios para configurar la agenda política es contingente, y depende de muchos factores: variables como el medio de comunicación estudiado, el asunto analizado, el criterio de selección y medición de la agenda política y el período temporal abarcado podrán, en sus múltiples combinaciones, arrojar resultados de investigación diferentes.

En una línea similar, se ha estudiado con frecuencia la capacidad del presidente (sobre todo de Estados Unidos) para establecer la agenda de los medios. Baumgartner y Jones (citado por Edwards y Barrett, 2000) afirman que ningún actor individual puede fijar la agenda de manera tan determinante como lo hace el presidente de Estados Unidos, al menos en su país. No obstante, del mismo modo que con los candidatos, la investigación parece apuntar a que las influencias son mutuas: el presidente condiciona la agenda mediática y los medios condicionan la agenda del presidente.

La personalidad de cada político también influye en su capacidad para dominar o ser dominado por la agenda. Evatt y Bell (citado por Tedesco, 2001), en un estudio sobre las elecciones a gobernador de Texas, concluyeron que la candidata Ann Richards conseguía establecer la agenda mediática, mientras que George Bush reaccionaba a ella. Otra de las variables que pueden influir en la dirección de la influencia (de los medios a los políticos o de los políticos a los medios) es el tema o asunto del que se trate. De este modo, hay asuntos en los que los medios presentan una mayor tendencia a dejarse influir, y otros en los que suelen llevar más la iniciativa. Wood y Peake (1998), en un trabajo sobre la imagen de los países extranjeros en los medios de comunicación estadounidenses y sus efectos políticos, encontraron un patrón de influencia desde los medios hacia la agenda presidencial, pero no al revés. Zhang y Meadows (2012) también encontraron un buen número de temas, como el sida, la educación y la conducción en estado de embriaguez, en los que los medios llevaron la iniciativa y lograron condicionar la agenda política.

Finalmente, la evolución de los medios digitales y el acceso cada vez más frecuente a las noticias a través de internet y redes sociales (Geiger, 2019) parece estar convirtiendo al usuario (audiencia) en un constructor más de la agenda o agenda-builder. Los periodistas y los medios reciben feedback constante e inmediato sobre lo que interesa o no a sus públicos a través de información verbal (como los comentarios en las noticias o las conversaciones en redes sociales) y no verbal (como el número de clicks en una noticia publicada o los likes y retweets a un determinado contenido) (Lee; Tandoc, 2017). La conducta de los usuarios condiciona así lo que los medios consideran importante y noticiable, alterando, al menos en parte, la dirección de los efectos clásicos de agenda hacia "efectos recíprocos" entre medios y audiencias (Ragas; Tran; Martin, 2014, p. 57; Tandoc; Vos, 2016). En otras palabras, se produce un fenómeno en dos pasos en el que los medios pueden estimular el interés público inicial en un asunto, y luego ser los públicos los que estimulen la cobertura informativa (McCombs; Shaw; Weaver, 2014). Por otra parte, los propios usuarios de los medios digitales se han convertido en parte en fuentes de información que dicen a otros usuarios "qué leer, cómo leerlo, y cómo responder a ellos" (Lee; Tandoc, 2017, p. 10), contribuyendo a un fenómeno de agenda setting más horizontal (McCombs; Shaw; Weaver, 2014). 


\section{Agenda setting en España}

La introducción de la agenda setting en la investigación en comunicación es un tanto tardía en España, pues no sería hasta 1996 (Canel; Llamas; Rey-Lennon, 1996) cuando se publican los primeros trabajos que empleaban esta teoría con rigor metodológico. Este retraso no fue sin embargo exclusivo o característico de la teoría de la agenda setting, ya que la creación de la comunicación como un campo académico propio en España fue más lenta que en los países de su entorno, e incluso posterior a su desarrollo en la mayoría de los países de América Latina (Ang et al., 2019).

Pese a la demora, las investigaciones publicadas en los noventa alcanzarían una elevada difusión internacional, gracias a la estrecha colaboración de algunos investigadores españoles con McCombs, con el que coordinaron diversos proyectos. Se trata de un grupo de académicos ligado a la Universidad de Navarra, liderado entonces por Esteban López-Escobar, y en el que destacaron María-José Canel, Juan-Pablo Llamas y Federico Rey, entre otros. La aportación española resultó especialmente relevante en el desarrollo del segundo nivel de la teoría. Uno de los primeros estudios empíricos explícitamente diseñados para evaluar la hipótesis sobre los efectos de la agenda de atributos se llevó a cabo en Navarra, en el contexto de las elecciones municipales y autonómicas celebradas en 1995. En este trabajo, McCombs et al. (1997) determinaron los efectos de agenda de los denominados "atributos sustantivos" de los candidatos (sus características de personalidad y su ideología y opiniones políticas) y también de los "atributos afectivos" (descripciones positivas, negativas y neutras de cada candidato). Uno de los hallazgos más importantes del estudio fue que la dimensión afectiva se transmitía de manera más intensa (mayor efecto de agenda) que la dimensión sustantiva.

Unos años más adelante, la investigación realizada en España volvería a resultar determinante para el desarrollo de otra de las extensiones del modelo original de la teoría. Rodríguez-Díaz (2004; 2010), en un giro teórico y metodológico innovador, estudió el papel de los profesores universitarios como agenda setters, "medios de comunicación" que transfieren la relevancia de los temas centrales de las materias que imparten, así como sus atributos, a sus audiencias: los alumnos. Con la colaboración del propio Maxwell McCombs, que codirigió la tesis de Rodríguez-Díaz (2001), la idea central de esta extensión de la teoría es que

"en el ámbito de la docencia es razonable pensar que son los profesores quienes influyen en los alumnos en lo que a sus expectativas sobre los programas o asignaturas se refiere" (Rodríguez-Díaz, 2001, pp. 291-202).

Sin embargo, las conclusiones de este estudio pionero parecen indicar que la influencia de la agenda del profesor en la agenda de los alumnos universitarios es menor de lo que podría esperarse. A partir del análisis de los datos de encuesta distribuidos entre alumnos de Periodismo la autora habla de una

"desconexión entre las agendas de los profesores y la de los alumnos" (Rodríguez-Díaz, 2001, p. 305).

Más recientemente, parte de la teorización y el desarrollo empírico del tercer nivel de la teoría ha contado con investigadores radicados en centros españoles, como la propia Raquel Rodríguez-Díaz (Universidad Rey Juan Carlos), Marta Martín-Llaguno (Universidad de Alicante) y Alberto Ardèvol-Abreu (Universidad de La Laguna), entre otros. Estos académicos colaboraron con el profesor McCombs en diversos estudios sobre el tercer nivel, que se sintetizan en el monográfico The power of information networks (Milena-Barrios et al., 2016; Saldaña; Ardèvol-Abreu, 2016; Ardèvol-Abreu; Saldaña; McCombs, 2013). Entre estas aportaciones cabe destacar el hallazgo de las "asociaciones convincentes" (compelling associations) en el tercer nivel de las teorías (Saldaña; Ardèvol-Abreu, 2016). Las asociaciones convincentes son asociaciones de varios atributos de un asunto (por ejemplo, delitos relacionados con las drogas e impacto de las drogas sobre los individuos) que cuando forman parte recurrente de la agenda de los medios, incrementan la importancia de ese asunto en la agenda del público (en el ejemplo anterior, las drogas). Se trata por tanto de un hallazgo que relaciona los tres niveles de la teoría: una red o conjunto (tercer nivel) de atributos de un objeto (segundo nivel) que, cuando forma parte de la agenda de los medios, aumenta la relevancia de un asunto en la agenda del público (primer nivel).

\subsection{Producción científica sobre agenda setting en España}

Tras cinco décadas de evolución de la agenda setting, con las múltiples ramificaciones de la idea central que se han mencionado en los epígrafes anteriores, se ha querido estudiar la vitalidad actual de la teoría en la investigación en Comunicación que se publica en España. Siendo este país ciertamente relevante en el desarrollo de algunas de las extensiones del modelo central, este apartado final pretende responder a las siguientes preguntas de investigación:

PI1: ¿En qué medida se sigue utilizando la teoría de la agenda setting en la producción científica en Comunicación publicada en España en el último quinquenio?

PI2: ¿En qué grado se utiliza el sustento teórico de la agenda setting para examinar la hipótesis central de la teoría (es decir, el fenómeno de transferencia de relevancia entre agendas)?

Para responder a estas preguntas, se llevó a cabo un trabajo de búsqueda sistemática y automatizada de contenidos, con el objetivo de localizar trabajos académicos originados (y publicados) en el país que contuviesen las palabras "agenda setting" o "agenda mediática". Tomando un criterio metodológico similar al de Ardèvol-Abreu (2015) para su estudio sobre el estado de la investigación en framing, se consideraron las revistas españolas indexadas en cualquier cuartil de CiteScore de Scopus ${ }^{9}$ en el área Social sciences - Communication (última actualización, basada en las citas obtenidas por las revistas en el año 2018, y referidas a documentos publicados en el período 2015-2017). Se ha añadido, además, la 
revista Profesional de la información, que a pesar de figurar en Scopus en el área de Social sciences - Library and information sciences, actualmente incorpora estudios sobre

"comunicación en general, así como métodos de gestión, visualización, preservación, etc., de la información periodística" (EPI, s.f.).

Para localizar las publicaciones, se lanzó una búsqueda a través del portal bibliográfico Dialnet ${ }^{10}$ con las palabras clave mencionadas, entrecomilladas y separadas por el operador lógico OR ${ }^{11}$. Se excluyeron los resultados anteriores al 30 de junio de 2014, para así establecer un período de análisis de 5 años (julio de 2014-julio de 2019)12. También se excluyeron los estudios que contuviesen las palabras de búsqueda que sólo nombraran, pero no trataran -de manera más o menos central- algún aspecto teórico o metodológico de la agenda setting. Se incluyeron inicialmente los artículos publicados en las revistas españolas de Comunicación, para luego añadir comunicaciones a congresos, libros y capítulos de libro y tesis doctorales. Ciertamente, este enfoque es sólo representativo de la investigación en agenda setting publicada en España, no así de los trabajos publicados por autores españoles. Y es que, en los últimos años, la disciplina se ha beneficiado de una creciente internacionalización, y los investigadores españoles en comunicación publican cada vez más en revistas de alto factor de impacto y editoriales de cualquier país. Y, por otro lado, investigadores extranjeros publican con cierta frecuencia en las revistas españolas de comunicación, sobre todo en aquellas con un mayor factor de impacto.

En el quinquenio junio 2014-junio 2019, se publicaron en las revistas seleccionadas un total de 34 artículos que cumplieron los criterios de búsqueda:

- 11 en Estudios sobre el mensaje periodístico,

- 6 en Communication \& society,

- 5 en Profesional de la información,

- 5 en Revista latina de comunicación social,

(ver el resto de las publicaciones en la tabla 1). Un número importante, teniendo en cuenta la gran variedad de teorías sobre efectos con las que ha de "competir" la agenda setting -de manera destacada, la teoría del framing-.

Tabla 1. Estudios que emplean la teoría de la agenda setting en revistas seleccionadas de comunicación españolas (30 jun. 2014-30 jun. 2019) Nota: Elaborado con datos de Dialnet.

\begin{tabular}{|c|c|}
\hline Revista & Autorias de los artículos sobre agenda setting \\
\hline Profesional de la información (EPI) & $\begin{array}{l}\text { - Roger-Monzó; Martí-Sánchez (2019) } \\
\text { - López-López; Vásquez-González (2018) } \\
\text { - Alonso-Muñoz; Casero-Ripollés (2018) } \\
\text { - Bouza-García; Tuñón-Navarro (2018) } \\
\text { - León-Gross; Rivera-Hernández; Redondo-Escudero (2018) }\end{array}$ \\
\hline Revista latina de comunicación social (RLCS) & $\begin{array}{l}\text { - Blanco-Castilla; Cano-Galindo (2019) } \\
\text { - Blasco-Duatis; Coenders-Gallart; Sáez-Zafra (2018b) } \\
\text { - Acosta-Peña; Brunet; Córdoba-Laguna (2017) } \\
\text { - Martínez-Garza; González-Macías; Miranda-Villanueva (2015) } \\
\text { - Fernández-Reyes; Piñuel-Raigada; Vicente-Mariño (2015) }\end{array}$ \\
\hline Communication \& society & $\begin{array}{l}\text { - Blasco-Duatis; Sáez-Zafra; Fernández-García (2018) } \\
\text { - Sormanen; Lauk; Uskali (2017) } \\
\text { - Flecha; Ortiz; Dones-González (2017) } \\
\text { - Mellado-Ruiz; Humanes (2017) } \\
\text { - Zunino (2016) } \\
\text { - López-García (2016) }\end{array}$ \\
\hline Catalan journal of communication \& cultural studies & - Agulló-Calatayud; Castelló-Cogollos; Valderrama-Zurián (2014) \\
\hline Historia y comunicación social & $\begin{array}{l}\text { - Cárdenas-Ruiz (2017) } \\
\text { - Casero-Ripollés (2015) }\end{array}$ \\
\hline Estudios sobre el mensaje periodístico & $\begin{array}{l}\text { - Jiménez-Sánchez; Vayas (2019) } \\
\text { - Melek; Ulucay (2019) } \\
\text { - Muñiz-Zúñiga (2018) } \\
\text { - Blasco-Duatis; Coenders-Gallart; Sáez-Zafra (2018a) } \\
\text { - Gallego-Ramos (2017) } \\
\text { - Dodds; Amor (2016) } \\
\text { - Odriozola-Chené; Aguirre-Mayorga; Bernal-Suárez (2016) } \\
\text { - Antón-Crespo; Alonso-del-Barrio (2015) } \\
\text { - Miranda-Villanueva; Iglesias-Ortiz (2015) } \\
\text { - Gómez-Patiño (2014) } \\
\text { - Rubio-García (2014) }\end{array}$ \\
\hline Revista científica de información y comunicación IC & - Hernández-Ruiz (2018) \\
\hline Icono 14 & - Torres-Nabel (2014) \\
\hline Trípodos & $\begin{array}{l}\text { - López-García; Cano-Orón; Argilés-Martínez (2016) } \\
\text { - Tous; Rivero-Santamarina; Meso-Ayerdi; Larrondo-Ureta /(2015) }\end{array}$ \\
\hline
\end{tabular}


Sin embargo, a pesar de esta relativa profusión de trabajos, un análisis más detallado de las publicaciones de este último quinquenio nos puede llevar a matizar las conclusiones. Así, casi un 60\% de los estudios recogidos en la tabla 1 (20 de ellos) aluden a la teoría en su marco teórico, o la utilizan para apuntalar sus resultados y conclusiones, sin realmente estudiar la hipótesis central de la agenda setting (el fenómeno de transferencia de relevancia entre agendas). Más concretamente, se hace referencia a la teoría para hacer análisis de la agenda de los medios (11 estudios), de la agenda política ( 3 estudios) o, más raramente, de la agenda del público (1 estudio), sin comprobar fenómenos de transferencia de relevancia entre unas y otras. En la mayoría de los casos se emplean técnicas cuantitativas o cualitativas de análisis de contenido para definir el tratamiento que los medios hacen de algún tema, o-menos frecuentemente-para estudiar la agenda de los públicos a través de la "conversación" que mantienen en redes sociales como Facebook o Twitter.

Como excepciones a este fenómeno general, algunos trabajos de los recogidos en la tabla 1 sí se han interesado por la hipótesis central de transferencia de relevancia. Aunque son minoría, diez de los artículos contienen alguna medida de los efectos postulados por la agenda setting:

- En un estudio clásico de primer nivel, Hernández-Ruiz (2018) analiza la transferencia de relevancia desde la agenda de temas "europeos" (es decir, relacionados con la UE) de los medios españoles de referencia hacia la agenda pública.

- Antón-Crespo y Alonso-del-Barrio (2015) llevan a cabo otro estudio del primer nivel, en el que encuentran que la agenda de los medios digitales afecta a la agenda del público de Twitter (medida a partir de los temas que son trending topic en esta red social).

- Desde un enfoque similar, Tous et al. (2015) abordan la interacción entre las agendas de los principales medios digitales españoles (medidas mediante análisis de contenido) y las de las audiencias (operativizadas mediante el estudio de los trending topics de cada día).

- También mediante análisis de contenido en Twitter, Rubio-García (2014) sostiene que la capacidad de los medios para marcar la agenda pública "depende y varía en función de los temas" (p. 262)-siendo las noticias de carácter político e internacionales las que más se transfieren a la agenda pública desde los medios tradicionales-.

- Un quinto trabajo, basado en el primer nivel de la teoría, constata mediante análisis de contenido cuantitativo que los principales periódicos españoles establecen la agenda del cambio climático al determinar el número de búsquedas en Google relacionadas con el calentamiento (agenda del público) (Fernández-Reyes; Piñuel-Raigada; Vicente-Mariño, 2015).

Otros de estos estudios han atendido a la transferencia de relevancia y las interacciones mutuas entre la agenda política y la mediática:

- Muñiz-Zúñiga (2018) encuentra una sincronización (a veces absoluta) entre las agendas política y mediática cubana a raíz de la muerte de Fidel Castro.

- Por su parte, Blasco-Duatis, Coenders-Gallart y Sáez-Zafra (2018b), desde la novedosa perspectiva metodológica del análisis composicional, abordan el fenómeno de la intermedia agenda setting -la manera en que unos medios condicionan la agenda de otros medios- en el ámbito político.

- En un estudio con algunas similitudes con el anterior, López-García, Cano-Orón y Argilés-Martínez (2016) abordan las influencias multidireccionales entre las agendas políticas de los dirigentes de la Comunidad Valenciana, los medios de comunicación y los líderes de opinión.

- Un único estudio se centró en el segundo nivel de la teoría, mediante el análisis de la transferencia de relevancia desde los medios hacia la opinión pública- de ciertos atributos referidos a la imagen de los refugiados sirios (Melek; Ulucay, 2019).

- Finalmente, Casero-Ripollés (2015) llevó a cabo un estudio cualitativo sobre el establecimiento inverso de la agenda, en el que encontró que los activistas políticos utilizan las redes sociales para captar la atención de los medios de comunicación y condicionar su agenda (transferencia de relevancia desde la agenda de los activistas hacia la agenda del público).

Por otra parte, se lanzó una nueva búsqueda en Dialnet para localizar capítulos en obras colectivas, libros y tesis doctorales $^{13}$ que trataran sobre la agenda setting o que la utilizaran en su marco teórico, empleando las mismas palabras clave que en el caso anterior. En cuanto a tesis doctorales, destaca claramente sobre los demás la producción científica de la Universidad Complutense de Madrid, con 8 tesis doctorales sobre agenda setting defendidas con éxito en el quinquenio (algo más de un $25 \%$ de todas las leídas en España). Los resultados obtenidos se muestran en la tabla 2.

A juzgar por el número de trabajos publicados en el quinquenio 2014-2019, la investigación basada en agenda setting y publicada en España no goza de mala salud 
Tabla 2. Ponencias en congresos, capítulos en obras colectivas, libros y tesis doctorales sobre agenda setting (30 junio 2014-30 junio 2019)

\begin{tabular}{|l|l|l|}
\hline Documento & \multicolumn{2}{|l|}{ Autoría / Universidad de lectura de la tesis } \\
\hline Ponencias en congreso & - Meso-Ayerdi et al. (2015) \\
& - Weinstein (2014) & \multicolumn{2}{|l|}{} \\
\hline Capítulos de libro & - & \multicolumn{2}{|l|}{} \\
\hline Libros & - & - Ferreres-Bertolín (2016), UVic \\
\hline \multirow{5}{*}{ Tesis doctorales } & - Sánchez-Lorenzo (2019), UNED & - García-Beyaert (2016), UAB \\
& - Cevallos-Ludeña (2018) UVigo & - Gil-Ramírez (2016), UMA \\
& - García-Lacroix (2018), UCM & - Gómez-Biedma-Gutiérrez (2016), US \\
& - Lamelas-López (2018), UPF & - Guzmán-Beltrán (2016), UCM \\
& - Arce-García (2017), UBU & - Labrín-Elgueta (2016), UCM \\
& - Hernández-Ruiz (2017), USPCEU & - López-López (2016), USC \\
& - Landete-Sánchez (2017), USPCEU & - Macedo-García (2016), UCM \\
& - Leal-Corral (2017), UCM & - Odeh-Madanat (2016), UOC \\
& - Linares-Lanzman (2017), UPF & - Parada-Gavilán (2016), UCM \\
& - Marín-Albaladejo (2017), UCSAM & - Quijano-Urreste (2016), UPV \\
& - Mora-Rodríguez (2017), UM & - Barrera-de-la-Cruz (2015), UCM \\
& - Nicasio-Varea (2017), UCHCEU & - Codinach-Fossas (2015), UAB \\
& - Ramírez-Leyva (2017), UMH & - Fenoll (2015), UV \\
& - Sanjurjo-García (2017), UAM & - López-Aira (2015), UCM \\
& - De-Souza-de-Almeida (2016), UAM & - Urzáiz-Duch (2015), US \\
\hline
\end{tabular}

Nota: Elaborado con datos de Dialnet.

Siglas de las universidades:

$U A B=$ Universitat Autònoma de Barcelona. UAM = Universidad Autónoma de Madrid. UBU = Universidad de Burgos. UCHCEU = Universidad CEU Cardenal Herrera. UCM = Universidad Complutense de Madrid. UCSAM = Universidad Católica San Antonio de Murcia. UHM = Universidad Miguel Hernández de Elche. UM = Universidad de Murcia. UMA = Universidad de Málaga. UNED = Universidad Nacional de Educación a Distancia. UOC $=$ Universitat Oberta de Catalunya. UPF = Universitat Pompeu Fabra. UPV = Universitat Politècnica de València. US = Universidad de Sevilla. USC $=$ Universidade de Santiago de Compostela. USPCEU = Universidad CEU San Pablo. UV = Universitat de València. UVic $=$ Universitat de Vic. UVigo $=$ Universidade de Vigo.

A juzgar por el número de trabajos publicados en un quinquenio, y excluyendo los estudios que realmente no son sobre agenda setting o no fueron publicados en España, parece que la investigación basada en esta teoría no goza de mala salud. Llama la atención el elevado número de tesis doctorales que utilizan la teoría de la agenda como fundamento teórico o metodológico (al menos 31 en sólo un quinquenio). Como principal déficit, se percibe un exceso de trabajos que utilizan las nociones de la teoría para llevar a cabo análisis de contenido sin llegar a plantear (empíricamente) ningún fenómeno de transferencia de relevancia. De manera similar, muchos de los trabajos publicados en el período 2014-19 se apoyan en el modelo más básico de la teoría, y muy pocos se centran en algunas de las extensiones del modelo original mencionadas en los apartados anteriores. Una vía aún poco explorada es el tercer nivel de la teoría, que brinda muchas posibilidades de desarrollo teórico y empírico a partir del análisis de la transferencia de relevancia de la agenda de asociaciones o redes de objetos y de atributos.

Después de más de cuarenta años de investigación continuada, la teoría ha dado muchos frutos, pero el principio general de transferencia de relevancia tiene aún largo recorrido (McCombs, 2006). La teoría no ha permanecido invariable, sino que progresivamente ha sido capaz de explicar más fenómenos empleando la misma idea central. Desde el inicial interés por explorar la influencia de la agenda de asuntos de los medios en la agenda del público, se pasó al estudio de los factores que limitaban o realzaban la influencia de los efectos del mensaje. Una tercera fase se centró en la influencia de las agendas externas sobre la agenda de los medios (agenda building). Más adelante el campo se movió hacia un intento de extrapolar el modelo de la agenda setting a otros procesos diferentes de la comunicación de masas, como la educación (véase, por ejemplo, Rodríguez-Díaz, 2001 y 2004). Finalmente, el tercer nivel de la teoría, planteado inicialmente hace ahora siete años, goza aún de un débil desarrollo empírico que puede constituir líneas interesantes de investigación.

\section{Notas}

1. Rodríguez-Díaz (2004, p. 17) recuerda que existen otras traducciones del término al castellano, que no han gozado de la misma aceptación. Destacan entre otras "función del establecimiento de una agenda temática", "jerarquización de noticias" o "canalización periodística de la realidad".

2. Este primer estudio de agenda setting (McCombs; Shaw, 1972) se centró en la campaña electoral para las elecciones presidenciales estadounidenses de 1968. Se buscó la correlación entre lo que el público consideraba como asuntos clave de la campaña (agenda del público) y los asuntos que los medios publicaban sobre ella (agenda de los medios). 
3. Habitualmente traducida al español como "teoría del flujo de comunicación en dos pasos" o "teoría del doble flujo de comunicación".

4. Consultar, por ejemplo, Althaus y Tewksbury (2002); Wang, (2000).

5. A pesar de esta tendencia general, existen hallazgos en sentido contrario. En ocasiones la agenda de la televisión ha demostrado ser más influyente que la de los periódicos (Weaver et al., 1981).

6. Se llama así al proceso de transferencia de relevancia entre emisores, por el que algunos medios prestigiosos condicionan la agenda de otros medios (López-Escobar et al., 1998).

7. Aunque existen más traducciones para obtrusive y unobtrusive, consideramos que experiencial y no experiencial (empleadas en la edición española de Setting the agenda [McCombs, 2006]) resultan las más adecuadas.

8. Los dos modelos explicativos fueron sintetizados por MacKuen y Coombs (1981), que distinguen entre el "modelo de la atención" y el "modelo del encuadre cognoscitivo". El primero sostiene que una mayor atención a la información y una mayor capacidad cognoscitiva aumentan la efectividad de la transferencia de relevancia, por lo que los individuos más formados serían más susceptibles a la agenda mediática. El modelo alternativo, denominado "del encuadre cognoscitivo", afirma que los individuos más atentos y con mayor capacidad cognoscitiva son los menos sensibles a la agenda de los medios, puesto que su marco de interpretación de los acontecimientos es sólido y resistente a influencias externas.

9. CiteScore está elaborado por Scopus y usa sus propios datos. Se ha creído conveniente utilizar el criterio más inclusivo de Scopus y no el de JCR de Web of Science por la reducidísima presencia de revistas españolas de Comunicación en este último sistema de indicadores. CiteScore puede consultarse en https://www.scopus.com/sources.uri

10. Se utilizaron comillas dobles en la búsqueda, con el objetivo de acotar los resultados a los documentos que contengan exactamente las palabras mencionadas, en el mismo orden. El operador lógico OR facilita resultados que contengan cualquiera de los términos de búsqueda. El buscador devuelve los documentos que incluyan estas palabras en el título, palabras clave o resumen.

11. Búsqueda lanzada los días 29 y 30 de junio de 2019 en el siguiente URL: https://dialnet.unirioja.es

Es posible que algunos de los trabajos sobre agenda setting publicados en España en el período de análisis no figuren entre los resultados obtenidos, pues Dialnet recoge una gran parte de las publicaciones científicas, pero no todas. También es posible, aunque sería extraño, que algún artículo que utilice la teoría no mencione los términos "agenda setting" o "agenda mediática" en el título ni en el resumen, ni en las palabras clave, pero sí lo haga más adelante. En este caso no figuraría entre los resultados obtenidos.

12. Aunque esta ventana temporal es arbitraria, creemos que es suficiente para reflejar el estado de la investigación más reciente. El criterio metodológico es similar al tomado por Ardèvol-Abreu (2015). Como sugerencia de investigación futura, un análisis más amplio debería analizar toda la producción científica española en el área a partir de 1996, año en que el equipo liderado por López-Escobar comenzó a publicar activamente sobre agenda setting.

13. La búsqueda se llevó a cabo en las mismas fechas del estudio de revistas, los días 28,29 y 30 de junio de 2019 . Se excluyeron los contenidos publicados fuera de España, así como los no centrados en aspectos comunicativos o que solo mencionasen la teoría, sin utilizarla realmente como fundamento teórico o metodológico.

\section{Referencias}

Acosta-Peña, Raúl A.; Brunet, Marcelo A.; Córdoba-Laguna, Juan-Carlos (2017). "La calidad de la información periodística de elespectador.com. El caso del Plebiscito por la Paz, 2016 en Colombia”. Revista latina de comunicación social, v. 72, n. 14, pp. 1502-1514.

https://doi.org/10.4185/RLCS-2017-1231

Agulló-Calatayud, Víctor; Castelló-Cogollos, Rafael; Valderrama-Zurián, Juan-Carlos (2014). "Beyond elite sports: Analysis of the coverage of anabolic steroids in the Spanish press (2007-2011)". Catalan journal of communication \& cultural studies, v. 6, n. 2, pp. 197-220.

https://doi.org/10.1386/cjcs.6.2.197_1

Alonso-Muñoz, Laura; Casero-Ripollés, Andreu (2018). “Communication of European populist leaders on Twitter: Agenda setting and the 'more is less' effect". El profesional de la información, v. 27, n. 6, pp. 1193-1202.

https://doi.org/10.3145/epi.2018.nov.03

Althaus, Scott L.; Tewksbury, David (2002). "Agenda-setting and the 'new' news. Patterns of issue importance among readers of the paper and online versions of the New York Times". Communication research, v. 29, n. 2, pp. $180-207$.

https://doi.org/10.1177/0093650202029002004 
Ang, Peng-Hwa; Knobloch-Westerwick, Silvia; Aguaded, Ignacio; Muñoz-Uribe, Juan F.; Wasserman, Herman; Athique, Adrian (2019). "Intellectual balkanization or globalization: The future of communication research publishing". Journalism \& mass communication quarterly, v. 96, n. 4, pp. 963-979.

https://doi.org/10.1177/1077699019878461

Antón-Crespo, Margarita; Alonso-del-Barrio, Estrella (2015). "El 'trending topic' frente a la 'agenda setting'". Estudios sobre el mensaje periodístico, v. 21, n. 2, pp. 23-34.

https://doi.org/10.5209/rev_ESMP.2015.v21.51125

Arce-García, Sergio (2017). La prevención de riesgos laborales y la accidentalidad laboral en la prensa española: representación y cobertura a partir de la Ley 31/1995 de prevención de riesgos laborales (1994-2014). Tesis doctoral. Universidad de Burgos.

https://dialnet.unirioja.es/servlet/tesis?codigo $=105848$

Ardèvol-Abreu, Alberto (2015). "Framing theory in communication research. Origin, development and current situation in Spain". Revista latina de comunicación social, n. 70, pp. 423-450.

https://doi.org/10.4185/RLCS-2015-1053en

Ardèvol-Abreu, Alberto; Saldaña, Magdalena; McCombs, Maxwell E. (2013). “Agenda-setting in the beginning of the 1979 oil crisis: compelling arguments and public concern". In: Annual Conference Association for Education in Journalism and Mass Communication (AEJMC), Washington DC.

Atkinson, Mary-Layton; Lovett, John; Baumgartner, Frank R. (2014). “Measuring the media agenda”. Political communication, v. 31, n. 2, pp. 355-380.

https://doi.org/10.1080/10584609.2013.828139

Barrera-de-la-Cruz, Gabriela (2015). México 2012: la revisión de las agendas. Tesis doctoral. Universidad Complutense de Madrid.

https://eprints.ucm.es/41647

Blanco-Castilla, Elena; Cano-Galindo, Juan (2019). "El acoso escolar y suicidio de menores en la prensa española: Del tabú al boom informativo". Revista latina de comunicación social, v. 74, n. 7, pp. 937-949.

http://www.revistalatinacs.org/074paper/1365/48es.html

Blasco-Duatis, Marc; Coenders-Gallart, Germà; Sáez-Zafra, Marc (2018a). "Representación composicional (CoDa) de la agenda setting de los opinantes sobre política en la prensa escrita española durante las elecciones generales de 2015". Estudios sobre el mensaje periodístico, v. 24, n. 2, pp. 1121-1146.

https://doi.org/10.5209/ESMP.62205

Blasco-Duatis, Marc; Coenders-Gallart, Germà; Sáez-Zafra, Marc (2018b). "Representación composicional de la intermedia agenda-setting de los principales grupos de medios y partidos políticos en las elecciones generales españolas de 2015". Revista latina de comunicación social, v. 73, n. 3, pp. 264-292.

https://doi.org/10.4185/RLCS-2018-1255

Blasco-Duatis, Marc; Sáez-Zafra, Marc; Fernández-García, Núria (2018). “Representación composicional (CoDa) de la agenda-setting de la opinión sobre política de los principales grupos de medios españoles en las elecciones generales de 2015". Communication \& society, v. 31, n. 2, pp. 1-23.

https://revistas.unav.edu/index.php/communication-and-society/article/view/35708

Bouza-García, Luis; Tuñón-Navarro, Jorge (2018). “Personalización, distribución, impacto y recepción en Twitter del discurso de Macron ante el Parlamento Europeo el 17/04/2018". El profesional de la información, v. 27, n. 6, pp. 1239-1247. https://doi.org/10.3145/epi.2018.nov.07

Bryant, Jennings; Miron, Dorina (2004). "Theory and research in mass communication". Journal of communication, v. 24, pp. 662-704.

https://doi.org/10.1111/j.1460-2466.2004.tb02650.x

Canel, María-José; Llamas, Juan-Pablo; Rey-Lennon, Federico (1996). "El primer nivel del efecto agenda-setting en la información local: los 'problemas más importantes' de la ciudad de Pamplona”. Communication \& society, v. 9, n. 1 y 2. https://revistas.unav.edu/index.php/communication-and-society/article/view/35626

Cárdenas-Ruiz, Juan-David (2017). “La crisis fronteriza colombo-venezolana en las pantallas: Análisis desde la comunicación política". Historia y comunicación social, v. 22, n. 2.

https://doi.org/10.5209/HICS.57854

Casero-Ripollés, Andreu (2015). "Estrategias y prácticas comunicativas del activismo político en las redes sociales en España". Historia y comunicación social, v. 20, n. 2, pp. 535-550.

https://doi.org/10.5209/rev_HICS.2015.v20.n2.51399 
Cevallos-Ludeña, Cinthya-María (2018). Los medios de comunicación ecuatorianos como actores políticos: una visión desde las teorías de swarming y agenda-setting en el caso del 30s. Tesis doctoral. Universidade de Vigo. https://dialnet.unirioja.es/servlet/tesis?codigo $=221755$

Codinach-Fossas, Mariona (2015). El tratamiento informativo de la inmigración marroquí en la televisión: el caso de Salt. Tesis doctoral. Universitat Autònoma de Barcelona. https://www.tdx.cat/bitstream/handle/10803/330924/mcf1de1.pdf

Cohen, Bernard C. (1963). The press and foreign policy. Princeton, NJ: Princeton University Press. ISBN: 9780877723462

Cowan, Nelson (2001). "The magical number 4 in short-term memory: A reconsideration of mental storage capacity". Behavioral and brain sciences, v. 24, n. 1, pp. 87-185.

https://doi.org/10.1017/S0140525X01003922

Danielian, Lucig H.; Reese, Stephen D. (1989). "A closer look at intermedia influences on agenda-setting: the cocaine issue of 1986". In: Shoemaker, Pamela J. (ed.). Communication campaigns about drugs: Government, media, and the public. New Jersey: Lawrence Erlbaum Associates, pp. 47-66. ISBN: 9780203052259

De-Moragas-Spà, Miquel (2013). Interpretar la comunicación: Estudios sobre medios en América y Europa. Barcelona: Gedisa. ISBN: 9788497846615

De-Souza-de-Almeida, Débora (2019). Prensa, opinión pública y política criminal en España: Un análisis sobre la posible influencia del populismo penal mediático en la aprobación de la prisión permanente revisable. Tesis doctoral. Universidad Autónoma de Madrid.

https://repositorio.uam.es/handle/10486/687152

Dodds, Tomás; Amor, Isabel-Margarita (2016). "Posicionamiento de las mujeres como locutoras en las transmisiones de programas radiales en Santiago de Chile". Estudios sobre el mensaje periodístico, v. 22, n. 2, pp. 981-993.

https://doi.org/10.5209/ESMP.54247

Edwards, George C. III; Barrett, Andrew (2000). "Presidential agenda-setting in Congress". In: Bond, Jon R.; Fleisher, Richard (eds.). Polarized politics: Congress and the President in a partisan era. Washington: CQ Press, pp. 109-134. ISBN: 9781568024943

EPI (s.f.). Información para los autores. El profesional de la información.

http://www.elprofesionaldelainformacion.com/autores.html

Fenoll, Vicente (2015). Los usuarios de los medios digitales ante los escándalos de corrupción. El caso del juicio de Francisco Camps. Tesis doctoral. Universitat de València.

Fernández-Reyes, Rogelio; Piñuel-Raigada, José-Luis; Vicente-Mariño, Miguel (2015). "La cobertura periodística del cambio climático y del calentamiento global en El país, El mundo y La vanguardia". Revista latina de comunicación social, n. 70, pp. 122-140.

https://doi.org/10.4185/RLCS-2015-1038

Ferreres-Bertolín, Marta (2016). El periodismo de salud en España: fuentes de información, periodistas y efectos de los mensajes publicados. Tesis doctoral. Universitat de Vic.

https://dialnet.unirioja.es/servlet/tesis?codigo=155989

Flecha, José A.; Ortiz, Maribel; Dones-González, Virgin (2017). "Risk communication. The media content effect on brain drain: The case of Puerto Rico". Communication \& society, v. 30, n. 3, pp. 93-107.

https://doi.org/10.15581/003.30.3.93-107

Gallego-Ramos, José-Raúl (2017). "Pensar los medios como organizaciones". Estudios sobre el mensaje periodístico, v. 23, n. 2, pp. 1089-1104.

https://doi.org/10.5209/ESMP.58034

García-Beyaert, Sofía (2016). Cross-linguistic communication and public policy: the institutionalization of community interpreting. Tesis doctoral. Universitat Autònoma de Barcelona.

https://www.tdx.cat/handle/10803/383765\#page=1

García-Lacroix, Cloe C. (2018). Tratamiento informativo del movimiento migratorio sirio reciente (2012-2015) en los diarios españoles $A B C$ y El país. Tesis doctoral. Universidad Complutense de Madrid.

https://eprints.ucm.es/56702/1/T41288.pdf

Geiger, Abigail W. (2019). "Key findings about the online news landscape in America". Factank. News in the numbers. Pew Research Center, 11 September.

https://www.pewresearch.org/fact-tank/2019/09/11/key-findings-about-the-online-news-landscape-in-america 
Gil-Ramírez, Marta (2016). Comunicación política. Campañas electorales e informativos. Elecciones autonómicas y municipales 2015. Hacia una regeneración democrática. Tesis doctoral. Universidad de Málaga.

https://riuma.uma.es/xmlui/handle/10630/11683

Golan, Guy (2006). "Inter-media agenda setting and global news coverage: Assessing the influence of The New York Times on three network television evening news programs". Journalism studies, v. 7, n. 2, pp. 323-333.

https://doi.org/10.1080/14616700500533643

Gómez-Biedma-Gutiérrez, María-José (2016). La información internacional en televisión: El caso de Canal Sur TV. Tesis doctoral. Universidad de Sevilla.

https://idus.us.es/handle/11441/41027

Gómez-Patiño, María (2014). “La influencia de la agenda setting: Análisis comparado del tratamiento del issue 'mujer' en la prensa española (2007-2012)”. Estudios sobre el mensaje periodístico, v. 20, n. 2, pp. 1103-1120.

https://doi.org/10.5209/rev_ESMP.2014.v20.n2.47052

Guo, Lei (2012). "The application of social network analysis in agenda setting research: A methodological exploration". Journal of broadcasting \& electronic media, v. 56, n. 4, pp. 616-631.

https://doi.org/10.1080/08838151.2012.732148

Guo, Lei (2013). "Toward the third level of agenda-setting theory. A network agenda setting model”. In: Johnson, Thomas J. (ed.). Agenda setting in a 2.0 World: new agendas in communication. New York: Routledge, pp. 112-133. ISBN: 9780 203735879

Guo, Lei (2016). "A theoretical explication of the network agenda setting model: current status and future directions". In: Guo, Lei; McCombs, Maxwell (eds.). The power of information networks. New directions for agenda setting. New York: Routledge, pp. 21-36. ISBN: 9781315726540

Guzmán-Beltrán, Ingrid-Jovana (2018). Los encuadres mediáticos durante la campaña electoral presidencial de Colombia 2014. Tesis doctoral. Universidad Complutense de Madrid.

https://eprints.ucm.es/42062

Hernández-Ruiz, Marta (2017). La Unión Europea en los medios de comunicación españoles: estudio de primer nivel de la teoría de la agenda setting. Tesis doctoral. Universidad San Pablo-CEU, Madrid.

https://dialnet.unirioja.es/servlet/tesis?codigo $=157043$

Hernández-Ruiz, Marta (2018). "La selección de temas sobre la Unión Europea en los medios de comunicación españoles. Estudio de campo de primer nivel de la teoría de la agenda setting". IC Revista científica de información y comunicación, n. 15, pp. 251-285.

https://idus.us.es/handle/11441/81391

Jiménez-Sánchez, Álvaro; Vayas, Eliza-Carolina (2019). “El fenómeno mediático de 'la chica del tranvía': ¿ romanticismo o acoso?". Estudios sobre el mensaje periodístico, v. 25, n. 1, pp. 303-316.

https://doi.org/10.5209/ESMP.63730

Katz, Elihu; Lazarsfeld, Paul F. (2006). Personal influence: The part played by people in the flow of mass communications. Transaction Publishers: New Jersey. ISBN: 9781412805070

Kim, Sei-Hill; Scheufele, Dietram A.; Shanahan, James (2002). "Think about it this way: attribute agenda-setting function of the press and the public's evaluation of a local issue". Journalism and mass communication quarterly, v. 79, n. 1 , pp. 7-25.

https://doi.org/10.1177/107769900207900102

Kosicki, Gerald M. (1993). "Problems and opportunities in agenda-setting research". Journal of communication, v. 43, n. 2, pp. 100-127.

https://doi.org/10.1111/j.1460-2466.1993.tb01265.x

Labrín-Elgueta, José-Miguel (2016). La coordinación de agendas y la función social de la prensa: la cobertura periodística de las campañas chilenas y de prevención y promoción de la salud. Tesis doctoral. Universidad Complutense de Madrid. https://eprints.ucm.es/42115

Lamelas-López, Marcos (2018). La mutación de la exclusiva. Mitos y realidades de la información propia en el periodismo español: de la pérdida de valor a la nueva dimensión 2.0. Tesis doctoral. Universitat Pompeu Fabra, Barcelona. https://www.tdx.cat/handle/10803/461795

Landete-Sánchez, Mercedes (2017). Mass media's impact on humanitarian intervention after the Cold War and before September $11^{\text {th }}$ 2001: the cases of Somalia, Rwanda and Liberia. Tesis doctoral. Universidad CEU San Pablo, Madrid. https://dialnet.unirioja.es/servlet/tesis?codigo=171299 
Le-Masurier, Megan (2015). “What is slow journalism?”. Journalism practice, v. 9, n. 2, pp. 138-152. https://doi.org/10.1080/17512786.2014.916471

Leal-Corral, Diego-Abraham (2017). La campaña presidencial de México 2012: agendas públicas, mediática y política. Tesis doctoral. Universidad Complutense de Madrid.

https://eprints.ucm.es/47809/1/T39967.pdf

Lee, Eun-Ju; Tandoc, Edson C. (2017). "When news meets the audience: How audience feedback online affects news production and consumption". Human communication research, v. 43, n. 4, pp. 436-44.

https://doi.org/10.1111/hcre.12123

León-Gross, Teodoro-Adolfo; Rivera-Hernández, Agustín; Redondo-Escudero, Myriam (2018). "International correspondents in Spain facing Government and information sources: Evaluation of problems by analytic hierarchy process (AHP)". El profesional de la información, v. 27, n. 4, pp. 813-821.

https://doi.org/10.3145/epi.2018.jul.10

Linares-Lanzman, Juan (2017). El 15M y los medios españoles. Análisis de redes temáticas en Twitter. Tesis doctoral. Universitat Pompeu Fabra, Barcelona.

https://dialnet.unirioja.es/servlet/tesis?codigo=172125

Lippmann, Walter (2003). La opinión pública. Madrid: Langre. ISBN: 9788493238131

López-Aira, Betty A. (2015). Análisis de la repercusión en los medios del nombramiento de Carme Chacón como ministra de Defensa. Tesis doctoral. Universidad Complutense de Madrid.

https://dialnet.unirioja.es/servlet/tesis?codigo=169882

López-Escobar, Esteban; Llamas, Juan-Pablo; McCombs, Maxwell E. (1996). “Una dimensión social de los efectos de los medios de difusión: agenda-setting y consenso". Comunication \& society, v. 9, n. 1-2, pp. 91-125.

https://revistas.unav.edu/index.php/communication-and-society/article/view/35631

López-Escobar, Esteban; Llamas, Juan-Pablo; McCombs, Maxwell E.; Rey-Lennon, Federico (1998). "Two levels of agenda-setting among advertising and news in the 1995 Spanish elections". Political communication, v. 15, n. 2, pp. 225-238. https://doi.org/10.1080/10584609809342367

López-García, Guillermo (2016). "'New' vs 'old' leaderships: the campaign of Spanish general elections 2015 on Twitter”. Communication \& society, v. 29, n. 3, pp. 149-167.

https://doi.org/10.15581/003.29.3.149-168

López-García, Guillermo; Cano-Orón, Lorena; Argilés-Martínez, Laura (2016). "Circulación de los mensajes y establecimiento de la agenda en Twitter: el caso de las elecciones autonómicas de 2015 en la Comunidad Valenciana". Trípodos, n. 39, pp. 163-183.

http://www.tripodos.com/index.php/Facultat_Comunicacio_Blanquerna/article/view/387

López-López, Paulo-Carlos (2016). A construción da axenda política, mediática e pública nas eleccións galegas do ano 2009: estratexia partidaria, produción da información e ciudadanía. Tesis doctoral. Universidade de Santiago de Compostela.

https://dialnet.unirioja.es/servlet/tesis?codigo=125093

López-López, Paulo-Carlos; Vásquez-González, Javier (2018). “Agenda temática y Twitter: elecciones presidenciales en América Latina durante el período 2015-2017". El profesional de la información, v. 27, n. 6, pp. 1204-1214. https://doi.org/10.3145/epi.2018.nov.04

Macedo-García, Alejandro (2016). La agenda setting y el framing en situaciones de crisis. Estudio de caso: la cobertura informativa en La Jornada y en Reforma sobre el desafuero del jefe de gobierno de la Ciudad de México. Universidad Complutense, Madrid.

https://eprints.ucm.es/42248/1/T38686.pdf

Mackuen, Michael B. (1984). “Exposure to information, belief integration, and individual responsiveness to agenda change". American political science review, v. 78, n. 2, pp. 372-391.

https://doi.org/10.2307/1963370

MacKuen, Michael B.; Coombs, Stephen L. (1981). More than news. Media power in public affairs. Beverly Hills: Sage. ISBN: 9780803915763

Marín-Albaladejo, Juan-Antonio (2017). La representación mediática del escándalo de corrupción política en España (2009-2014) desde la teoría del encuadre (framing). Tesis doctoral. Universidad Católica San Antonio de Murcia.

http://repositorio.ucam.edu/handle/10952/2528 
Martínez-Garza, Francisco J.; González-Macías, Rubén A.; Miranda-Villanueva, Óscar M. (2015). “Actores políticos y sociales de los telediarios: Una tarea pendiente de las televisoras mexicanas". Revista latina de comunicación social, v. 70, pp. 750-764.

https://doi.org/10.4185/RLCS-2015-1069

McCombs, Maxwell E. (1992). "Explorers and surveyors: expanding strategies for agenda-setting research". Journalism quarterly, v. 69, n. 4, pp. 813-824.

https://doi.org/10.1177/107769909206900402

McCombs, Maxwell E. (2002). "The agenda-setting role of the mass media in the shaping of public opinion". In: Mass Media Economics Conference. London School of Economics, London.

https://www.infoamerica.org/documentos_pdf/mccombs01.pdf

McCombs, Maxwell E. (2005). “A look at agenda-setting: past, present and future". Journalism studies, v. 6, n. 4, pp. 543-557.

https://doi.org/10.1080/14616700500250438

McCombs, Maxwell E. (2006). Estableciendo la agenda. El impacto de los medios en la opinión pública y en el conocimiento. Barcelona: Paidós. ISBN: 9788449318696

McCombs, Maxwell E.; Evatt, Dixie (1995). “Los temas y los aspectos: explorando una nueva dimensión de la agenda-setting". Communication \& society, v. 8, n. 1, pp. 7-32.

https://revistas.unav.edu/index.php/communication-and-society/article/view/35616

McCombs, Maxwell E.; Llamas, Juan-Pablo; López-Escobar, Esteban; Rey-Lennon, Federico (1997). “Candidate images in Spanish elections: second level agenda-setting effects". Journalism and mass communication quarterly, v. 74, n. 4, pp. 703-717.

https://doi.org/10.1177/107769909707400404

McCombs, Maxwell E.; Shaw, Donald L. (1972). "The agenda-setting function of mass media”. The public opinion quarterly, v. 36, n. 2, pp. 176-187.

https://doi.org/10.1086/267990

McCombs, Maxwell E.; Shaw, Donald L. (1977). "Structuring the 'unseen environment'”. Journal of communication, v. 26, n. 2, pp. 18-22.

https://doi.org/10.1111/j.1460-2466.1976.tb01374.x

McCombs, Maxwell E.; Shaw, Donald L.; Weaver, David H. (2014). "New directions in agenda-setting theory and research". Mass communication and society, v. 17, n. 6, pp. 781-802.

https://doi.org/10.1080/15205436.2014.964871

McLeod, Jack M.; Becker, Lee B.; Byrnes, James E. (1974). "Another look at the agenda-setting function of the press". Communication research, v. 1, n. 2, pp. 131-166.

https://doi.org/10.1177/009365027400100201

Melek, Gizem; Ulucay, Dilek M. (2019). “Atributos de los medios de comunicación y cambio de actitud: experimentos sobre el impacto del establecimiento de la agenda de segundo nivel sobre las actitudes hacia los refugiados sirios". Estudios sobre el mensaje periodístico, v. 25, n. 1, pp. 381-393.

https://doi.org/10.5209/ESMP.63735

Mellado-Ruiz, Claudia; Humanes, María-Luisa (2017). “Homogeneity and plurality of the media agenda in Chile. A crosslongitudinal study of the national print press between 1990 and 2015". Communication \& society, v. 30, n. 3, pp. 75-92. https://revistas.unav.edu/index.php/communication-and-society/article/view/35770

Meraz, Sharon (2011). "Using time series analysis to measure intermedia agenda setting influence in traditional media and political blog networks". Journalism and mass communication quarterly, v. 88, n. 1, pp. 176-194.

https://doi.org/10.1177/107769901108800110

Meso-Ayerdi Koldobika; Rivero-Santamarina, Diana; Tous, Anna; Larrondo-Ureta, Ainara (2015). “Del porqué las redes sociales revolucionan la agenda setting de los medios". En: Cortiñas-Rovira, Sergi; Elduque, Albert; Alonso-Marcos, Felipe; Darriba-Zaragoza, Marc (coords.). Actas del XX Congreso de la Sociedad Española de Periodística, Periodismo actual y futuro: investigación, docencia e innovación. Barcelona: Universitat Pompeu Fabra, pp. 460-475. ISBN: 9788460690931 https://dialnet.unirioja.es/servlet/articulo?codigo $=6088007$

Milena-Barrios, Marta M.; García, Victor; Guo, Lei; Wang, Qian; Aksamit, Radoslaw; Guzek, Damian; Jachimowsky, Marek; Ardèvol-Abreu, Alberto; Martín-Llaguno, Marta; Rodríguez-Díez, Raquel; Chen, Yi-Ning K.; McCombs, Maxwell; Vu, Hong (2016). "News coverage of the Iraq War. An international comparison of network attribute agendas". In: Guo, Lei; McCombs, Maxwell (eds.). The power of information networks. New directions for agenda setting. New York: Routledge, pp. 144-158. ISBN: 9781315726540 
Miranda-Villanueva, Óscar-Mario; Iglesias-Ortiz, Ángel (2015). “Agenda-setting de medios en la guerra contra las drogas". Estudios sobre el mensaje periodístico, v. 21, n. 1, pp. 403-420. https://doi.org/10.5209/rev_ESMP.2015.v21.n1.49102

Mohamed, Hamza; Gunter, Barrie (2009). "Agenda-setting in a quasi-democratic country: a case study of Egypt". Journal of Arab and Muslim media research, v. 2, n. 1, pp. 135-158.

https://doi.org/10.1386/jammr.2.1and2.135/1

Mora-Rodríguez, Alberto (2017). El voto económico y estudio de agendas en España: aproximación a sus efectos en las elecciones generales del 2000 y 2011. Tesis doctoral. Universidad de Murcia.

https://digitum.um.es/digitum/bitstream/10201/52979/1/TESIS-Alberto\%20Mora.pdf

Muñiz-Zúñiga, Viviana (2018). "Repercusión de la muerte de Fidel Castro en Santiago de Cuba. Aparición y evolución del 'event' en las agendas política y mediática”. Estudios sobre el mensaje periodístico, v. 24, n. 1, pp. 797-816. https://doi.org/10.5209/ESMP.59980

Nicasio-Varea, Blanca (2017). La ayuda internacional y la agenda mediática antes y después del terremoto de Haití. Estudio comparado de la respuesta política, periodística y ciudadana (2008-2012). Tesis doctoral. Universidad CEU - Cardenal Herrera, Valencia.

https://dialnet.unirioja.es/servlet/tesis?codigo $=186270$

Odeh-Madanat, Philip (2016). The role of Friday sermon in shaping the opinion of the worshippers in Jordan. Tesis doctoral. Universitat Oberta de Catalunya, Barcelona.

http://openaccess.uoc.edu/webapps/o2/handle/10609/56305

Odriozola-Chené, Javier; Aguirre-Mayorga, Consuelo; Bernal-Suárez, Juan-David (2016). “Condicionantes en la calidad de los contenidos de los cibermedios ecuatorianos: convergencia periodística, agenda temática e inmediatez". Estudios sobre el mensaje periodístico, v. 22, n. 2, pp. 1103-1121.

https://doi.org/10.5209/ESMP.54254

Parada-Gavilán, Carolina A. (2016). Eficacia de los sitios webs de los diputados chilenos como herramienta de la comunicación política. Tesis doctoral. Universidad Complutense de Madrid.

https://eprints.ucm.es/42206

Park, Robert E. (1940). "News as a form of knowledge: A chapter in the sociology of knowledge". American journal of sociology, v. 45, n. 5, pp. 669-686.

https://doi.org/10.1086/218445

Price, Vincent; Tewksbury, David (1997). "News values and public opinion: A theoretical account of media priming and framing". In: Barnett, George A.; Boster, Franklin J. (eds.). Progress in communication sciences: advances in persuasion. Greenwich, CT: Ablex, pp. 173-212. ISBN: 9781567502770

Protess, David L.; McCombs, Maxwell E. (eds.) (1991). Agenda-setting: readings on media, public opinion and policy making. New Jersey: Erlbaum. ISBN: 9780805808414

Quijano-Urreste, John F. (2016). Análisis de la imagen del pueblo colombiano en la prensa nacional española a través del léxico. Tesis doctoral. Universitat Politècnica de València.

https://riunet.upv.es/handle/10251/68504

Quillian, Ross (1968). "Semantic memory". In: Minsky, Marvin (ed.). Semantic information processing. Cambridge: MIT Press. ISBN: 9780262516853

Ragas, Matthew W.; Tran, Hai L.; Martin, Jason A. (2014). “Media-induced or search-driven? A study of online agenda-setting effects during the BP oil disaster". Journalism studies, v. 15, n. 1, pp. 48-63.

https://doi.org/10.1080/1461670X.2013.793509

Ramírez-Leyva, Flor M. (2016). Encuadres noticiosos de la salud en los informativos de la televisión pública y privada en México. Tesis doctoral. Universidad Miguel Hernández de Elche.

https://dialnet.unirioja.es/servlet/tesis?codigo=110335

Rodríguez-Díaz, Raquel (2001). Los profesores universitarios como medios de comunicación: la 'agenda-setting' de los alumnos y profesores. Tesis doctoral. Universidad Complutense de Madrid.

http://eprints.ucm.es/tesis/inf/ucm-t24877.pdf

Rodríguez-Díaz, Raquel (2004). Teoría de la agenda-setting: aplicación a la enseñanza universitaria. Alicante: Observatorio Europeo de Tendencias Sociales.

http://rua.ua.es/dspace/handle/10045/2297 
Rodríguez-Díaz, Raquel (2010). "Setting students' professional agenda in the classroom". Central European journal of communication, v. 3, n. 5, pp. 299-311.

http://www.cejc.ptks.pl/Volume-3-No-2-5-Fall-2010/Setting-students-professional-agenda-in-the-classroom

Rodríguez-Díaz, Raquel; Castromil, Antón R. (2010). “La circulación social de los encuadres periodísticos en tiempo de campaña electoral: transmisión, influencia y atribución de responsabilidad”. Zer, v. 15, n. 29, pp. 193-210.

https://www.ehu.eus/ojs/index.php/Zer/article/view/1652/0

Roger-Monzó, Vanessa; Martí-Sánchez, Myriam (2019). “Estudio longitudinal sobre el tratamiento de la homeopatía en la prensa digital española (2012-2016)". El profesional de la información, v. 28, n. 2, e280216.

https://doi.org/10.3145/epi.2019.mar.16

Rubio-García, Raquel (2014). "Twitter y la teoría de la agenda-setting: mensajes de la opinión pública digital”. Estudios sobre el mensaje periodístico, v. 20, n. 1, pp. 249-265.

https://doi.org/10.5209/rev_ESMP.2014.v20.n1.45230

Saldaña, Magdalena; Ardèvol-Abreu, Alberto (2016). "From compelling arguments to compelling associations at the third level of agenda setting". In: Guo, Lei; McCombs, Maxwell (eds.). The power of information networks. New directions for agenda setting. New York: Routledge, pp. 104-118. ISBN: 9781315726540

Sánchez-Lorenzo, Jesús (2019). Opinión pública libre, opinión publicada: La libertad de comunicación pública y los medios de comunicación. Tesis doctoral. Universidad Nacional de Educación a Distancia (UNED).

http://e-spacio.uned.es/fez/view/tesisuned:ED-Pg-UniEuro-Jsanchez

Sanjurjo-García, Diego (2017). Multiple streams and multiple couplings in Latin American public policies: Understanding gun policy changes in Brazil and Uruguay. Tesis doctoral. Universidad Autónoma de Madrid.

https://repositorio.uam.es/handle/10486/683278

Shaw, Donald L.; Martin, Shannon E. (1992). "The function of mass media agenda-setting". Journalism quarterly, v. 69, n. 4, pp. 902-920.

https://doi.org/10.1177/107769909206900410

Sormanen, Niina; Lauk, Epp; Uskali, Turo (2017). “Facebook's ad hoc groups: a potential source of communicative power of networked citizens". Communication \& society, v. 30, n. 2, pp. 77-95.

https://doi.org/10.15581/003.30.2.77-95

Stone, Gerald C.; McCombs, Maxwell E. (1981). "Tracing the time lag in agenda-setting”. Journalism quarterly, v. 58, n. 1, pp. 51-55.

https://doi.org/10.1177/107769908105800108

Tandoc, Edson C.; Vos, Tim P. (2016). "The journalist is marketing the news: Social media in the gatekeeping process". Journalism practice, v. 10, n. 8, pp. 950-966.

https://doi.org/10.1080/17512786.2015.1087811

Tedesco, John C. (2001). "Issue and strategy agenda-setting in the 2000 presidential primaries". American behavioral scientist, v. 44, n. 12, pp. 2048-2067.

https://doi.org/10.1177/00027640121958483

Torres-Nabel, Luis-César (2014). “El poder de las redes sociales: la 'mano invisible' del framing noticioso. El caso de \#LadyProfeco". Icono 14, v. 12, n. 2, pp. 318-337.

https://doi.org/10.7195/ri14.v12i2.625

Tous, Anna; Rivero-Santamarina, Diana; Meso-Ayerdi, Koldobika; Larrondo-Ureta, Ainara (2015). "Ambient journalism in Spain. How Twitter and NREs are redefining agenda setting in El país, El mundo, La razón, ABC, and La vanguardia". Trípodos, n. 36, pp. 35-54.

http://www.tripodos.com/index.php/Facultat_Comunicacio_Blanquerna/article/view/241

Urzáiz-Duch, Luis-Jorge (2015). La responsabilidad social empresarial en la prensa del siglo XXI. Tesis doctoral. Universidad de Sevilla.

https://dialnet.unirioja.es/servlet/tesis?codigo $=46547$

Vu, Hong-Tien; Guo, Lei; McCombs, Maxwell E. (2014). “Exploring 'the world outside and the pictures in our heads': A network agenda-setting study". Journalism \& mass communication quarterly, v. 91, n. 4, pp. 669-686.

https://doi.org/10.1177/1077699014550090

Walgrave, Stefaan; Van-Aelst, Peter (2006). "The contingency of the mass media's political agenda-setting power: Toward a preliminary theory". Journal of communication, v. 56, n. 1, pp. 88-109.

https://doi.org/10.1111/j.1460-2466.2006.00005.x 
Wang, Tai-Li (2000). "Agenda-setting online: An experiment testing the effects of hyperlinks in online newspapers". Southwestern mass communication journal, v. 15, n. 2, pp. 59-70.

Wanta, Wayne (1997). The public and the national agenda. How people learn about important issues. New Jersey: Lawrence Erlbaum Associates. ISBN: 9780805824612

Wanta, Wayne; Golan, Guy; Lee, Cheolhan (2004). "Agenda-setting and international news: media influence on public perceptions of foreign nations". Journalism and mass communication quarterly, v. 81, n. 2, pp. 364-377. https://doi.org/10.1177/107769900408100209

Watt, James H.; Mazza, Mary; Snyder, Leslie (1993). “Agenda-setting effects on television news coverage and the effects decay curve". Communication research, v. 20, n. 3, pp. 408-435.

https://doi.org/10.1177/009365093020003004

Weaver, David H.; Graber, Doris A.; McCombs, Maxwell E.; Eyal, Chaim H. (1981). Media agenda-setting in a presidential election. New York: Praeger. ISBN: 9780030590665

Weinstein, Mary (2014). "Espaço do patrimônio em meio à profusão de noticias". En: Mancinas-Chávez, Rosalba; Nogales-Bocio, Antonia-Isabel (coords.). Actas del I Congreso Internacional Infoxicación: Mercado de la Información y Psique. Sevilla: Facultad de Comunicación, pp. 829-847.

https://idus.us.es/handle/11441/33282

Winter, James P.; Eyal, Chaim H. (1981). “Agenda-setting for the civil rights use”. Public opinion quarterly, v. 45, n. 3, pp. 376-383.

https://doi.org/10.1086/268671

Winter, James P.; Eyal, Chaim H.; Rogers, Ann H. (1982). "Issue-specific agenda-setting: the whole as less than the sume of the parts". Canadian journal of communication, v. 8, n. 2, pp. 1-10.

https://doi.org/10.22230/cjc.1982v8n2a268

Wolf, Mauro (2000). La investigación de la comunicación de masas: crítica y perspectivas. Barcelona: Paidós. ISBN: 84 75094376

https://catedracoi2.files.wordpress.com/2014/05/wolf-mauro-investigacion-de-la-comunicacion-de-masas.pdf

Wood, B. Dan; Peake, Jeffrey S. (1998). "The dynamics of foreign policy agenda-setting". American political science review, v. 92, n. 1, pp. 173-184.

https://doi.org/10.2307/2585936

York, Chance (2013). "Overloaded by the news: Effects of news exposure and enjoyment on reporting information overload". Communication research reports, v. 30, n. 4, pp. 282-292.

https://doi.org/10.1080/08824096.2013.836628

Zhang, Cui; Meadows, Charles W. (2012). "International coverage, foreign policy, and national image: exploring the complexities of media coverage, public opinion, and presidential agenda". International journal of communication, v. 6 , pp. 76-95.

https://ijoc.org/index.php/ijoc/article/view/1424

Zhu, Jian-Hua (1992). "Issue competition and attention distraction: a zero-sum theory of agenda-setting". Journalism quarterly, v. 69, n. 4, pp. 825-836.

https://doi.org/10.1177/107769909206900403

Zunino, Esteban (2016). "La valoración de las noticias políticas en la agenda mediática: una propuesta metodológica para el análisis de contenido". Communication \& society, v. 29, n. 4, pp. 235-254.

https://doi.org/10.15581/003.29.4.sp.235-254

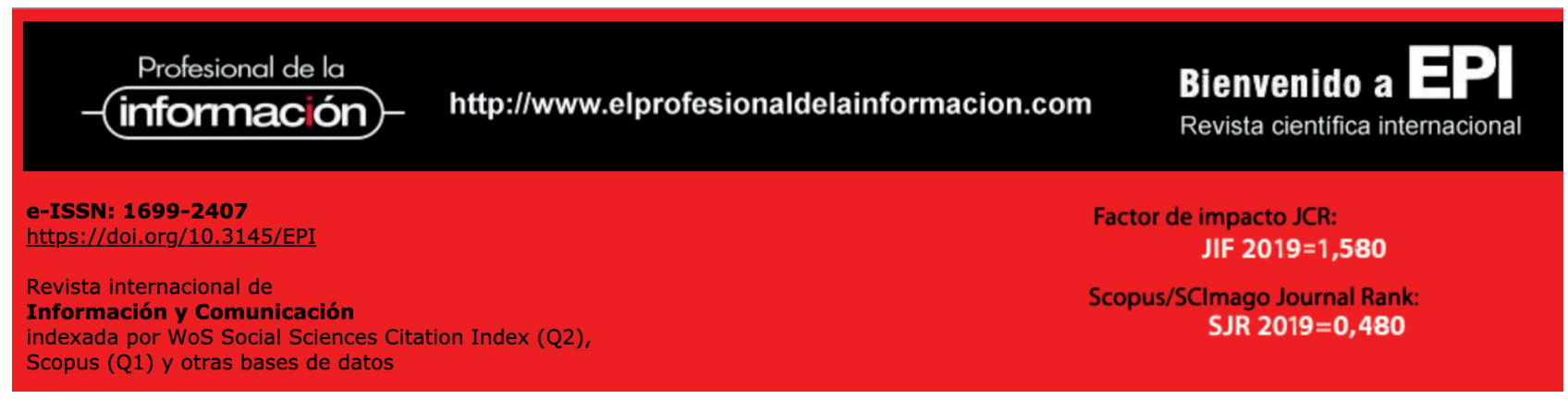

